\title{
Inflation Targeting and Target Instability
}

\author{
Robert J. Tetlow* \\ Board of Governors of the Federal Reserve System \\ Washington, DC 20551 \\ December 29, 1999
}

\begin{abstract}
Monetary policy is modeled as being governed by a known rule, except for a time-varying target rate of inflation. The variable target is taken as representing either discretionary deviations from the rule, or as the outcome of a policymaking committee that is unable to arrive at a consensus. Stochastic simulations of FRB/US, the Board of Governors' large, rational-expectations model of the U.S. economy, are used to examine the benefits of reducing the variability in the target rate of inflation. We find that putting credible boundaries on target variability introduces an important non-linearity in expectations. The effect of this is to improve policy performance by focussing agents' expectations on policy objectives. But improvements are limited; it does not generally pay to reduce target variability to zero. More important, this non-linearity in expectations allows for policy to be conducted, at the margin, with greater attention to output stabilization than would otherwise be the case. The results provide insights as to why inflation targeting countries use bands and why the bands they use are narrower than studies suggest they should be. A side benefit of the paper is the demonstration of a numerical technique that approximates to arbitrary precision a non-linear process with a linear method, thereby greatly speeding and making more robust the computation of simulation results.
\end{abstract}

JEL CODES: E3, E5, C6. KEYWORDS: monetary policy, inflation targeting, macroeconomic modeling

* Correspondence: e-mail: Robert.J.Tetlow@frb.gov. telephone: (202) 452-2437 facsimile: (202) 452-5296. snail mail: Mailstop 61. The views expressed in this paper should not be attributed to the Board of Governors, the FOMC or staff members of the Federal Reserve System. I am thankful for the comments of Steve Ferris, Ben Hunt, Tiff Macklem, Athanasios Orphanides, Dave Reifschneider, Larry Schembri, John C. Williams and seminar participants at Carleton University, the Bank of Canada and the Reserve Bank of Australia. Frederico S. Finan contributed his usual excellent research assistance. All remaining errors are my own. An earlier version of this paper was titled 'Reducing Randomness in Inflation Targeting'. 


\section{Introduction}

While the pursuit of price stability does not rule out misfortune, it lowers its probability...If households are convinced of price stability, they will not see variations in relative prices as reasons to change their long-run inflation expectations. Thus, continuing to make progress toward this legislated objective will make future supply shocks less likely and our nation's economy less vulnerable to those that occur.

\section{Alan Greenspan \\ The Federal Reserve's Semiannual Monetary Policy Report February 28, 1998}

In recent years, a number of countries have adopted inflation targeting as the "legislated objective" for their countries, in pursuit of the same bounty that Alan Greenspan, the Chairman of the Federal Reserve describes in the above quotation taken from his February 1998 Humphrey-Hawkins testimony. ${ }^{1}$ New Zealand (1990), Canada (1991), the United Kingdom (1992), Sweden (1993) and Finland (1993) have all established explicit targets for inflation. By itself, inflation targeting is not a controversial issue. Most economists would accept that a monetary authority's overriding responsibility is to establish and maintain a nominal anchor. In one sense, targeting inflation is simply the most direct and obvious means for establishing the anchor. Belying this apparent simplicity, however, are some important operational issues. Does it suffice to make broad statements about "price stability" being the ultimate objective of policy, without defining quantitatively what the term means, as the Federal Reserve has done? What about announcing a range of indifference, within which any rate of inflation is as good as any other, as in the case of Australia? And what of the much more specific and confining regimes of the United Kingdom and New Zealand $?^{2}$ Would degrees of commitment of this nature achieve better results? ${ }^{3}$

1. The Humphrey-Hawkins testimony takes its name from the legislation, named for its sponsors, that requires semi-annual appearances by the Chairman before the House and Senate Banking Committees. The Chairman was alluding to an updating of the mandate of the Fed which, under the current law, calls for a broad list of objectives and the pursuit of monetary targets. Currently, neither the Fed nor the Banking Committees pay much attention to the targets for monetary aggregates although they are still reported. 
As Chairman Greenspan's statement emphasizes, and as Bernanke et al. (1999) document for a variety of countries, the purpose of public declarations regarding policy objectives appears to be two-fold: (1) to direct private agents' expectations towards policy objectives; and (2) to establish a method of public accountability for central bank policy making. In this paper, we examine what role a limited form of policy credibility--specifically, the idea that inflation targets might drift within bounds over time--might have on monetary policy outcomes and for policy choices.

In modeling variability in the target rate of inflation, what we have in mind is the perception of private agents with regard to the medium- to long-term objectives of policy. Presumably, perceptions of policy objectives will coincide, in the long run, with actual policy. But, given that policy preferences and the determinants of policy actions are not directly observable, there is considerable latitude for discretionary actions, inactions, or policy errors, in the short run.

This 'slippage' between how policy is practiced and how it is perceived to operate can affect the trade-offs that monetary authorities face and, as a consequence, the choices they make. Bernanke et al. (1999, pp. 59-61) emphasize the short-term flexibility that the Bundesbank enjoys in its day-to-day operations as a result of the widely held perception that they will maintain a constant medium-term nominal anchor. Goodfriend (1991) argues that the credibility of the Fed can under some circumstances be counted on to bring about desired movements in long-term nominal and real interest rates in anticipation of fed funds rate movements that may or may not be forthcoming. It is this idea, that expecta-

2. In the case of the U.K., when the Labour government took power, it granted operational autonomy to the Bank of England, narrowed the inflation band to plus-or-minus one percentage point, and required the Bank to provide a written, public explanation for any breaches of the target bands. In New Zealand, the government adopted target bands with a provision that the Governor would be dismissed if the bands were breached and the explanation for it was deemed unsatisfactory.

3. Siklos (1997) provides a nice short summary of the practices of various inflation targeting countries, see especially the table on pp. 132-133.

1. Introduction 
tions of future policy actions can be built up and used to improve economic outcomes that is explored in this paper.

We investigate this issue using the Federal Reserve Board's rational expectations macroeconometric model of the U.S. economy, FRB/US. We conduct stochastic simulations using the model to provide a quantitative guide to the possible benefits that might be accrued with a regime where there is randomness in policy but only within bounds. As we shall see, target bands for inflation control imply an important nonlinearity. This fact, combined with the large scale of the FRB/US model, presents a challenging problem in numerical analysis. The resolution of this numerical problem is, we believe, a significant contribution of the paper.

Our main thrust, however, is on the popular notion that expectations of future policy actions can be divorced, at the margin at least, from current policy actions. This possibility cuts both ways, of course: Most of the countries that have adopted inflation target bands did so because they had been unsuccessful in credibly implementing another, different sort of policy regime. These countries were seeking a regime that forestalled any impression that abandoning their former regime implied drift in policy objectives. ${ }^{4}$ In the U.S. example, one might argue that the Federal Reserve has already accrued a reputation that is useful for providing some added latitude to pursue objectives other than short-term control of inflation. Whether this good reputation can survive a period of "misfortune" as Chairman Greenspan describes above, is an open question.

The rest of the paper proceeds as follows. In Section 2 we discuss variability in monetary policy, and how the behavior of central banks in general and the Federal Reserve

\footnotetext{
4. The U.K. settled on its initial regime of inflation targeting in 1992 after an unsuccessful attempt to remain in the ERM under pressure. The Bank of England and the Chancellor have since adapted the makeshift program of 1992 to a more cohesive campaign. New Zealand ended up on an inflation targeting regime after falling off a fixed exchange rate regime. Of the countries with formal inflation targets Canada is the only country not to have selected an inflation targeting regime under duress.
} 
in particular might be reasonably characterized by drifting but bounded targets for inflation. We also describe how 'variability' is operationalized for this paper. The third section provides a brief encapsulation of the FRB/US model. Section 4 then discusses aspects of our simulation technique. The fifth section summarized our results. A sixth section sums up and concludes.

\section{Inflation Targeting and Variable Targets}

\subsection{Policy rules and policy objectives}

There are a number of ways in which one might characterize policy. The most formal is as the solution to a dynamic optimization problem with well-defined preferences and a well-specified model. Another quite different method is where decision makers 'look out the window' to see whether the economy is currently running 'too hot' or 'too cold' and adjust policy stance accordingly. ${ }^{5}$ If the policy that arises out of the former method is known by the public and rigidly adhered to, it is an example of policy by rules. In contrast, making decisions by looking out the window is inherently discretionary. ${ }^{6}$

Between these two extreme characterizations of policy lie a wide range of alternatives embodying differing levels of commitment and flexibility. The introduction to this paper, for example, notes the popularity of target bands as a device to contain inflation expectations. Other devices, such as the former exchange-rate mechanism of European Union countries, attempt to achieve the same goal using somewhat different methods.

Suppose, for example, the public had information about the broad objectives of policy--as there is for the Federal Reserve with respect to its obligations under legislation and from widely reported speeches of Board members--but no information regarding a

5. Term 'looking out the window' comes from Alan Blinder (1998) where in his chapter 1 he describes the Federal Open Market Committee as containing elements of this kind of policy making. The tone of his monograph, however, makes it fairly clear that he is not suggesting that this is the sole basis for policy decisions at the Fed.

6. The FOMC began, in 1994, releasing an immediate public statement when it raised or lowered the target for the federal funds rate. 
specific rule governing policy. Fed watchers might be driven to fit a policy rule to the data in an effort to impute a reaction function of the FOMC. One such effort along these lines is the rule advanced by John Taylor. The Taylor (1993) rule is promoted by its author as both a good rule, in that it avoids policy instability, and a rule that fits the pattern of funds rate setting "remarkably well," (p. 202) at least over the period from 1987 to 1992.

In the time since its publication, the Taylor rule has garnered a good deal of attention. The "lessons" of the Taylor rule are reported to at least some members of the Board as "principles to guide decisions about the setting of the federal funds rate at FOMC meetings" (Meyer 1998b, p. 16). And at least four current and past Board governors have specifically mentioned it in speeches to the public. ${ }^{7}$ At the same time, each of these governors has taken great pains to indicate that the Fed does not follow the Taylor rule and that no rule could do justice to the complexity of factors that are weighed by the FOMC. ${ }^{8}$

The Taylor rule is very simple:

$$
R_{t}=2+\tilde{\pi}_{t}+0.5\left(\tilde{\pi}_{t}-2\right)+0.5 y_{t}
$$

It sets the nominal federal funds rate, $R$, equal to the equilibrium nominal rate--that is, the equilibrium real rate, $r r^{*}$, taken by Taylor to equal 2 percent as shown, plus expected inflation, proxied by a four-quarter moving average of the quarterly annualized change in the GDP deflator, $\tilde{\pi}$--plus two disequilibrium terms. One of these disequilibrium terms is the discrepancy of actual inflation from the target with the target assumed by Taylor to be equal to 2 percent; the other disequilibrium term is the output gap, $y$. Taylor (1993) emphasizes that the output gap can enter the equation either as a proxy for expected future

7. A computer search of speeches by Board members for the words "Taylor rule" and derivatives thereof reveals twelve hits for speeches by governors Meyer, Gramlich, Ferguson and Yellen. No other rule has ever been publicly cited in speeches, an observation that lends some credence for our use of the Taylor rule in this section.

8. Here is a more-or-less standard disclaimer, in this case from Meyer (1997, p. 20) "I do not want to mislead you about the degree to which I believe we can rely on any single rule in general or my commitment to the Taylor Rule in particular. But the Taylor Rule helps illustrate some important aspects of monetary policy strategy." 
inflation, since output statistically causes inflation, or because stabilizing output is an objective of policy in its own right.

It is instructive to examine a measure of fit of the Taylor rule. We do this not as a criticism of the rule, but as an indication of the discrepancy between policy as it has actually been conducted historically, and as it has been described. Other rules would obviously give different answers, but no parsimonious rule would significantly alter the point to be made below. For our purposes it is most useful to measure the goodness of fit of the Taylor rule by taking its specification as given and solving out for the implied target inflation rate as in Figure 1.

There is much that could be said about this implied target, but we wish to focus on just three things. First, there has clearly been a shift in either the equilibrium real interest rate or the target rate of inflation, or both, in the early 1980s. ${ }^{10}$ This helps explain Taylor's focus on the 1987-1992 period as one where the fit is remarkable. Second, over both subsamples there have been large and persistent movements in the implied target rate of inflation. High frequency movements in $\pi^{*}$ could be attributed to a missing term from the rule, associated perhaps with tactical concerns in conducting policy, or control errors. But movements as persistent as those shown are difficult to ascribe to something other than changes in the target, or the implied target, of policy. Third, with the exception of the once-and-for-all shift at around 1980 or so, the shifts in the implied target, however persistent, appear to have been bounded within ranges.

9. We have replaced the implicit price deflator used in Taylor (1993) with the chain-weight index that is now used by the Bureau of Economic Analysis for the National Income and Product Accounts. Otherwise, our formulation is the same as Taylor's.

10. It is likely that both a shift in $\pi^{*}$ and a shift in $r r^{*}$ occurred. The early 1980s was the period of the Volcker disinflation in which CPI inflation was deliberately brought down by the Fed from about 12 percent to approximately 5 percent. Bomfim (1997) shows that the equilibrium real interest rate apparently rose at about the same time, perhaps due to the accumulation in the early 1980s of large public sector deficits. 
Figure 1

Target Rate of Inflation as Implied by the Taylor Rule

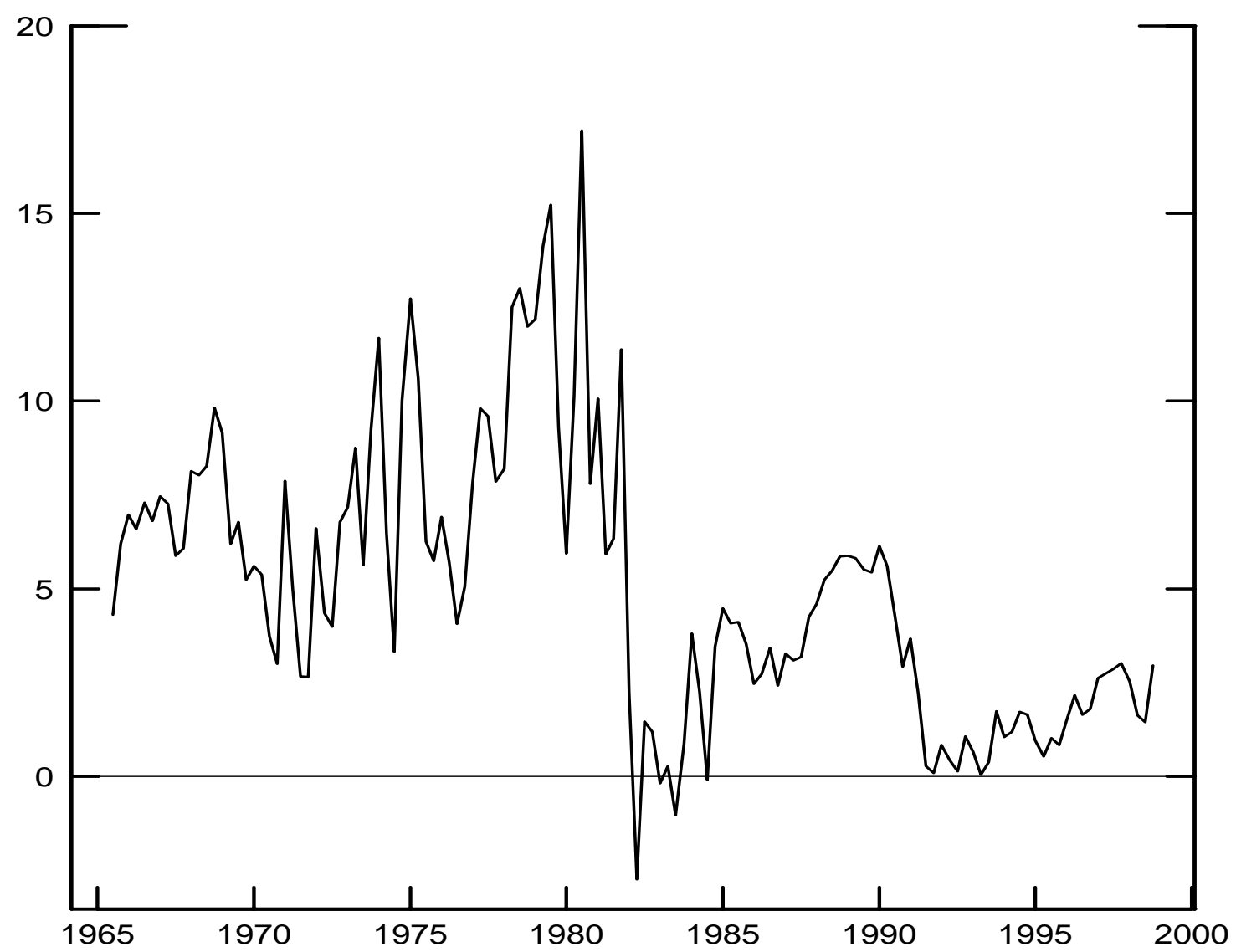

Figure 1 supports the notion that the implicit target rate of inflation has been subject to considerable randomness, at least from the perspective of one popular rendition of the systematic portion of U.S. monetary policy. That this is at least a plausible characterization of policy is supported by the observation that the Fed does not regularly or systematically consider the advice of policy rules themselves, or even explicitly discuss the quantitative objectives of policy. ${ }^{11}$ This means that the target of policy has been a latent

11. The FOMC is on record as having an objective of price stability, and indeed is obliged to target this according to the Humphrey-Hawkins legislation, but has said nothing on what this might mean. 
variable of policy--something that falls out of funds rate settings given the stochastic shocks that are borne by the economy--rather than the other way around.

The control-theoretic perspective on policy design has the monetary authority choosing the target rate of inflation based on objective time-invariant criteria and then using that target rate as an input to a dynamic optimization problem that furnishes a feedback rule as an end product. Discretion will have a tendency to do the opposite. For example, when the Fed, in pursuing discretionary policy, failed in the 1970s to adjust the funds rate sufficiently in response to inflationary shocks, the implication was that the target rate of inflation was being increased--not necessarily as a deliberate act of policy as perhaps an implication of the Fed's unwillingness to forgo output objectives in order to maintain a fixed inflation target. While the story differs in some ways from a deliberate, exogenous change in the target rate of inflation, the effect is very close to the same in the context of a stochastic economy. ${ }^{12}$

Orphanides and Wilcox (1996) describe something similar to this in their paper on "opportunistic disinflation" as a description of Fed behavior in the 1990s. ${ }^{13}$ An opportunistic policymaker does not fix his or her target rate of inflation exogenously and simply pursue it; rather, the target rate is a function of the underlying shocks to which the economy is subject. If inflationary shocks are experienced, the target rate remains fixed. If disinflationary shocks hit the economy, the Fed accommodates the shocks by reducing the target rate of inflation. This is precisely the same as what happened in the late 1960s and 1970s, except that the sign is the opposite: in the 1960s and 1970s inflationary shocks

12. This characterization of policy in the 1970 s is consistent with that of Clarida et al. (1998) and Chari et al. (1999). It is also consistent with the rhetoric of Meltzer (1991) when he accuses the Fed of having lost control of inflation because FOMC "members were reluctant to allow interest rates to rise by as much as required by staff forecasts. They hoped to achieve lower inflation by reducing money growth but were reluctant to allow interest rates rise by relatively large steps" (p.34).

13. It is noteworthy that opportunistic disinflation was the name that a Federal Reserve governor, Laurence Meyer, gave to the policy he saw the FOMC following when he joined the Board early in 1995. The Orphanides and Wilcox paper was written as a theoretical explanation of Meyer's observation. See Meyer (1997) for a description of opportunistic disinflation including the author's claim to paternity. 
were accommodated and disinflationary ones were fought off. This resulted in the upward creep over the 1970s in the implied target as shown in Figure 1.

It is worth emphasizing that the theory of Orphanides and Wilcox (1996) was an effort to explain the apparent reluctance of the FOMC to adjust the funds rate with anywhere near the frequency and magnitude that quantitative normative assessments of policy would suggest. In the context of a policy rule like equation (1), if the funds rate is fixed, the only other object that can vary over time is the target rate of inflation.

Quantitative work by Orphanides et al. (1997) provided a quantitative assessment of both opportunistic disinflation, and a symmetric extension of the concept that permits drift, within bounds, of actual inflation while the Fed concerns itself with output stabilization, and then strong inflation control at the edges of the band. This describes a 'zone of indifference' regarding inflation--not unlike the policy practiced by Australia--and might be rationalized by committee structures that can agree on a point when inflation is 'too high' or 'too low', but cannot come to a consensus on intermediate cases.

The next subsection models inflation targets as a bounded, random process. To summarize the arguments of this subsection, what we have in mind by this process is an implied drift in target brought about by the historical reluctance of the Fed to respond to shocks--except when inflation 'gets out of hand'. Our favored explanation for this behavior is that it is the outcome of the consensus-oriented decision-making process of the Federal Open Market Committee. ${ }^{14}$ Under this interpretation, the upper and lower boundaries for the target rate of inflation are points at which a critical mass on the committee would say that trend inflation is out of line with long-term objectives. In between, there might be more of a bias toward going back to a zero target--in the sense that the probabilities point

14. The practice of decision-making by consensus at the FOMC is well known. See, e.g., Blinder (1998) and Meyer (1998b). Blinder notes that this can lead to sluggish responses. As we shall argue below, it may also lead to a disconnection between long-term objectives and short-term practices of the Fed. 
in that direction--but not an overwhelming impetus. Some committee members might be inclined to pursue other objectives or--more consistent with the historical record--to await further information (and more shocks) before acting. At the midpoint of the bands, all FOMC members are agreed that inflation is not a problem.

There are, however, other ways to think of this reluctance to react, and the target drift it implies. It can, for example, be regarded as an attempt to practice short-term discretion, as an effort to evade public criticism for controversial actions, or as a response to uncertainty. And these alternative explanations are not mutually exclusive. However, it is beyond the scope of this paper to discuss the range of explanations for these observations. Whatever the ultimate source, we would argue that the lack of a clearly articulated policy objective, together with an absence of a demonstrable commitment to a time-invariant policy, will elicit variability in private agents' perceptions of target inflation over time.

\subsection{Modeling inflation target bands}

The preceding subsection has established at least a prima facie case for treating the target of monetary policy as a random variable. In this subsection, we operationalize this idea for simulation purposes. We begin by assuming that monetary policy can be described by a simple interest-rate reaction function, as follows:

$$
R_{t}=r r^{*}+\sum_{i=0}^{3} \pi_{t-i} / 4+3.0\left[\sum_{i=0}^{11} \pi_{t-i}-\pi_{t}^{*}\right]+0.9 y_{t}
$$

where, as before, $R$ is the nominal federal funds rate, $r r$ is the real rate, $\pi$ is quarterly inflation measured at annual rates, $y$ is the output gap and an asterisk indicates the equilibrium or target level of a variable, as applicable. Equation (2) is similar to the Taylor rule, discussed above, but differs in three ways. First, the rule's inflation term is expressed as a twelve-quarter moving average of inflation instead of four quarters. Williams (1999) shows that, in the context of FRB/US, equations with longer lags on inflation outperform shorter lags. Second, the coefficients on both inflation and the output gap are larger for our 
rule. In fact, Williams (1999) shows that this parameterization is an efficient one in that no other coefficient values can produce lower unconditional variances of output and inflation simultaneously without increasing the variability of the federal funds rate. ${ }^{15}$ Formally, equation (2) is the solution to a problem that minimizes the following loss function:

$$
E_{0} \sum_{i=1}^{\infty} \varphi\left[\tilde{\pi}_{t+i}-\pi_{t+i}{ }^{*}\right]^{2}+(1-\varphi) y_{t+i}^{2}
$$

subject to the model, a constraint on the functional form of the rule, namely that of equation (2), and to a constraint on maximum variability of the federal funds rate. ${ }^{16}$ By choosing a (constrained) optimal rule in this way we avoid specious results that might arise simply from the use of a poorly performing rule. In addition, we have the advantage of being able to consider policymakers' preferences directly. Equation (2) is the (constrained) optimal rule for an authority with relatively 'hawkish' inflation preferences: $\varphi=0.75$; we shall examine alternative preferences a bit later.

The third difference from the Taylor rule is that the target rate of inflation, $\pi_{t}{ }^{*}$, carries a time subscript. We allow time variation in the monetary policy target and assume that private agents only know the actual target with a one quarter lag. ${ }^{17}$ We consider two possible data generating processes for the target rate of inflation: a random walk and a bounded random walk. ${ }^{18}$ Clearly no authority would truly permit the target rate of infla-

15. Equation (2) also dominates rules with shorter moving averages in the inflation rate as judged by the same criterion of minimized unconditional variances. Note that we have arbitrarily rounded the many decimal places used in the rule actually used for simulation for expositional simplicity. 16. Having some sort of penalty on funds rate variability provides two benefits: (1) the optimally computed coefficients on the policy rule are of a magnitude that would be considered reasonable; and (2) the implied variability of the federal funds rate is close to the historical experience. The same qualitative results obtain when funds rate volatility is mildly penalized instead of the hard constraint we use here.

17. As discussed below, private agents know the target with a one-quarter lag because they are assumed to know the policy rule. This means that they can simply invert the rule on a quarter-toquarter basis to find out what the target was in the previous period.

18. The results from ADF tests regarding the order of integration of the price level depend on the number of lags permitted and the precise span of data tested. In any case, the premise behind this paper is that the monetary authority can choose the order of integration even if it has, at times in the past, elected not to do so. 
tion to vary from plus to minus infinity, so the pure random walk case should be thought of as a benchmark. In both cases, the law of motion for the target looks the same:

$$
\pi^{*}{ }_{t}=\pi^{*}{ }_{t-1}+\mu_{t}
$$

The difference is in the distribution of innovations. In the pure random walk case, the innovations, $\mu_{t}$, are independently and identically distributed:

$$
\mu_{t} \sim N\left(0, \sigma^{2}\right)
$$

In the bounded random walk case, innovations are bounded by the target bands. Letting $\bar{\pi}^{*}$ and $\underline{\pi}^{*}$ designate the upper and lower bounds for $\pi^{*}$, Johnson et al. (1994, p. 156) show that the (truncated) probability density function of innovations is: ${ }^{19}$

$$
\mu_{t} \sim \frac{1}{\sigma \sqrt{2 \Pi}} \exp \left[\frac{-\mu^{2}}{2 \sigma^{2}}\right]\left\{\frac{1}{\sigma \sqrt{2 \Pi}} \int_{\left(\pi^{*}-\pi^{*}{ }_{t-1}\right)}^{\left(\bar{\pi}^{*}-\pi^{*}{ }_{t-1}\right)} \exp \left[-\frac{\left(t-\pi^{*}{ }_{t-1}\right)^{2}}{2 \sigma^{2}}\right] d t\right\}^{-1}
$$

As ugly as equation (6) looks, it is simply a a truncated normal distribution, with truncation points determined by band widths and the inherited rate of target inflation, given $\sigma$. That is, the truncation points, $\left\{\pi^{*}-\pi^{*}{ }_{t-1}, \bar{\pi}^{*}-\pi^{*}{ }_{t-1}\right\}$ shift around with the inherited target inflation rate. We assume that the bands are spaced symmetrically around a given midpoint, which we can set to zero without loss of generality. Let us also assume that the bands on the target rate of inflation are +1 and -1 percent respectively, as in our base-case simulations below. When the inherited target inflation rate happens to be zero, the distribution of innovations is simply the normal distribution with the tails beyond +1 and -1 chopped off. Besides being symmetric, with our base-case value of $\sigma$ of 0.25 , this distribution is functionally identical to the normal distribution because the truncation points are four standard deviations away. When the inherited target rate of inflation is positive, the upper bound on innovations moves to the right, eliminating more of the positive innova-

19. The $\Pi$ appearing in two terms of equation (6) should not be confused with the symbol for inflation, $\pi$, used elsewhere. 
tions that would otherwise be possible, and adding more of the negative innovations. If the inherited target rate of inflation were exactly 1 percent, the distribution of possible innovations would be exactly one-half of the normal distribution. ${ }^{20}$

The case of a fixed target rate of inflation is nested within equation (6), as $\underline{\pi}^{*}=\bar{\pi}^{*}=0$. In addition, permitting $\bar{\pi}^{*} \rightarrow \infty$ and $\underline{\pi}^{*} \rightarrow-\infty$ gives the pure random walk case.

It is important to note that these boundaries for the target do not imply the same boundaries for inflation itself. In the short run, many forces are at work on inflation of which only one is monetary policy. Moreover, monetary policy is not solely concerned with stabilizing inflation. Lastly, even in the presence of a fixed objective, inflation is buffeted by shocks from a variety of sources such that only if each shock can be instantaneously identified and policy can be tailored explicitly for each shock could inflation be controlled perfectly. Thus, in general, inflation itself will be more variable than the target.

Two issues regarding the law of motion for $\pi^{*}$ warrant discussion. The first of these is the assumption that $\pi^{*}$ moves randomly within the target bands. If one thinks of the drifting target as representing discretion, it might be preferable to allow target innovations to be correlated with other shocks. However, as discussed above in the period prior to the Volcker disinflation, time variation in the de facto preferences of the Fed does not appear to have arisen from a conscious selection of different priorities. Instead it appears to have come from an unwillingness to respond to shocks with sufficient strength to be consistent with a constant target. Indeed, the tendency in that period was, in the words of the Fed's Director of Monetary Affairs, to "adjust nominal rates too slowly in the initial

\footnotetext{
20. We are modeling a discrete-time version of what is sometimes called reflecting barriers. With reflecting barriers, that proportion of the distribution of targets that would have called for targets outside of the bands is discarded. An alternative is absorbing barriers in which the truncated portion of the distribution is assigned to the boundary value causing a tendency for target rates of inflation to mass at the boundary edges. With reflecting barriers, the target rate of inflation almost never reaches the boundary, as we shall see. Dixit (1993) provides a thorough discussion of the mathematics and modeling of both types of barriers in continuous time.
} 
stages of a cycle, and then to overstay a policy stance" while awaiting further information. ${ }^{21}$ While the process that Kohn alludes to will produce a correlation with shocks, it is only to the extent of the sign of the shocks--upward in the 1960 and 1970s, and downward in the 1990s. In this context, the assumption adopted here does not seem like an egregious oversimplification. $^{22}$

Finally, and ultimately, the process we have selected to represent time variation in the target rate of inflation is both simple to understand and tractable from a numerical perspective. Allowing innovations to the target rate of inflation that are correlated with state variables or other shocks would oblige us to adopt non-recursive solution techniques which would be prohibitively slow to compute. ${ }^{23}$

The second issue is that we also assume that the bounds on the target are regarded as fully credible by private agents. This amounts either to assuming that there is a commitment technology that prevents violations of the bands, or that a record of inflation performance has earned the monetary authority a reputation for controlling its target. ${ }^{24} \mathrm{~A}$ commitment technology might arise out of the nomination process for Board members. Presidential nomination and Senate approval may be viewed as vetting candidates for the minimum level of intolerance for inflation variability. Reputation might be earned by establishing an appropriate track record for performance, and buttressed by making monetary policy sufficiently transparent that imprecise control can be distinguished from timevarying preferences.

21. Kohn (1991, p. 101). As Meyer (1998b, p. 18-19) notes, it is the Director of Monetary Affairs that presents the policy options to the FOMC. Kohn is also the Secretary to the Federal Open Market Committee.

22. We might also note that to the extent to which innovations to the target were systematically correlated with shocks or other state variables, it should show up in the specification of the rule itself. And to the extent these shocks are correlated with the output gap, they may already be captured in the Taylor rule coefficient for that variable.

23. We note as well that this specification for the target rate of inflation allows a straightforward comparison of our results with those of the exchange-rate target-band literature which is related to the modeling undertaken here.

24. There is a huge literature on credibility and commitment in monetary policy games, beginning with the seminal contributions of Kydland and Prescott (1977) and Barro and Gordon (1983). 


\subsection{Expected future inflation targets}

In the preceding subsection, the target rate of inflation was modeled with a truncated normal distribution. The truncation at any given date is determined entirely by (1) the inherited target inflation rate; (2) the variance of innovations; and (3) the band width. In this subsection, we describe the expected future target rate of inflation conditional of some initial value. The nature of this expectation is key to the results that follow because in the FRB/US model, expected future target rates of inflation feed into current price- and wage-setting behavior.

Private agents are assumed to know the process for the target rate of inflation, but not the current value of innovations. Since they know the inherited target inflation rate, the expected value of the current target can be computed, $E_{t-1} \pi_{t}^{*}$. And because innovations are independent, this value can then be taken as given and a value for $E_{t-1} \pi_{t+1} *$ can be computed, and so on, in a straightforward application of the chain rule of forecasting.

As we have already noted, at the midpoint of the bands the truncation is symmetric, the truncation points being equally distant from the inherited target rate. It follows that $E_{t-1} \pi^{*}{ }_{t+j}=\pi_{t-1}{ }^{*}=0$ : the pure random walk prediction obtains in this special case. It was also noted that when $\pi^{*}=\bar{\pi}^{*}=1$, the entire upper half of the normal distribution is truncated and only the lower half is pertinent. It follows that the complete distribution of future target inflation rates is (weakly) less than the current target and so the optimal prediction is for a decline in the future target. The same argument applies for inherited targets at the lower bound, except of course with the opposite sign. Everywhere in between these two extremes, there are varying degrees of asymmetric truncation, but as a general proposition it is clear that (i) the expected future target approaches the midpoint of the bands as time approaches infinity; and (ii) the initial rate of reversion toward the midpoint will be vary positively with the proximity of the inherited target rate to the bound, given the stan- 
dard deviation of innovations. Note as well that private agents' expectations of inflation targets are entirely consistent with the modeling of actual targets.

Johnson et al. (1994, pp. 156-162) show how to compute the probability density function for the truncated normal. Based on this, Figure 2 shows the expected future path of $E_{t-1} \pi^{*}{ }_{t+j}$ for three initial values of $\pi^{*}{ }_{t-1}$, given $\sigma=0.25$, and symmetric bands with the upper value arbitrarily set at $\bar{\pi}^{*}=1 .^{25}$

The expected future path of target rates of inflation depends only on $\pi^{*}{ }_{t-1}, \bar{\pi}^{*}$ and $\sigma$. Larger values of $\sigma$ produce stronger non-linearities because of higher probabilities of truncation for any given inherited target rate (other than zero). Symmetrically increasing the width of the target band, $\bar{\pi}^{*}-\underline{\pi}^{*}$, has the opposite effect.

Figure 2

Agents' Inflation-Target Forecasts (bounded random walk, width $=+/-1$ )

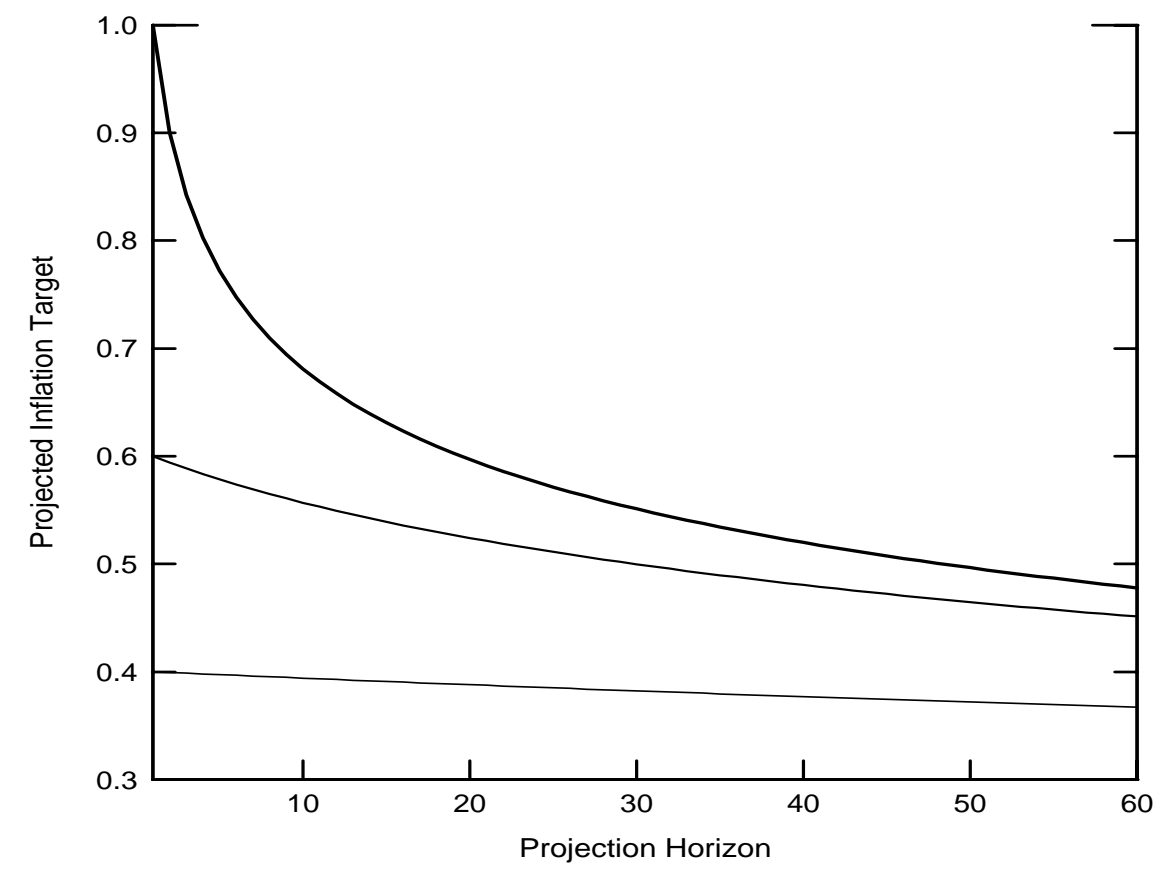

25. The standard deviation of innovations of 0.25 percent taken from the standard deviation of changes in the Philadelphia survey of inflation expectations, 10 years ahead, our proxy for the public's expectation of inflation in the long term. 


\section{The FRB/US Model}

In this section we outline the basic features of the FRB/US model, focusing mostly on those aspects that are germane to the issues studied in this paper, and describe some of the model's properties. ${ }^{26} \mathrm{FRB} / \mathrm{US}$ is a relatively large rational expectations structural model consisting of about 30 key behavioral equations and several hundred identities. It features forward-looking behavior in asset prices, wages and goods prices, and consumption and investment spending. Rigidities in wage and price setting imply that monetary policy has effects on the real economy in the short-run, but in the long run, policy can affect only the inflation rate.

At its heart, FRB/US is a neoclassical growth model. That is, once all dynamic adjustment is complete, the model settles down on a balanced growth path with consumption determined by wealth, wealth determined for the most part by productivity and steady-state real interest rates, and real interest rates determined by the savings-investment decisions of private agents in concert with government.

The model is non-Ricardian. Of the several reasons which account for this feature, the most important is that risk-averse agents 'overdiscount' their future disposable income, in the same spirit as the Blanchard (1985) model of perpetual youth. For this reason, among others, fiscal policy can act upon the long-run equilibrium of the economy through purchases, transfers, government debt, and distortionary taxes.

FRB/US is designed around the joint-determination of private-sector expectations and public policy. In pursuit of this goal, about half of the model's dynamic behavioral equations are explicitly derived as decision rules governing the behavior of representative agents acting with foresight to achieve explicit objectives in the presence of constraints. In

26. Limitations of space prevent us from doing justice to the features of the FRB/US model here. Interested readers should consult Brayton and Tinsley (eds.) (1996) on general aspects of the model. Particularly accessible descriptions of the modeling of expectations, and the monetary policy transmission mechanism, respectively, are Brayton et al. (1997) and Reifschneider et al. (1999). An application of the model to the analysis of disinflations is Bomfim et al. (1997). 
the special case of the asset price equations, adjustment costs are taken as negligible, so that arbitrage relationships determine outcomes. More generally, forward-looking agents plan in advance to adjust the value of their decision variables to converge over time on (possibly moving) target levels, while balancing the cost of being away from the desired level against the cost of adjustment. This is a key feature of the model as it pertains to the simulation exercises in this paper. Adjustment costs mean that private agents must plan in advance to set out a path for wages and prices that minimize those costs. These plans are conditional on expected future demand conditions, relative prices, and policy actions, including the expected future target rate of inflation. Thus, expectations of future targets affect current decisions and determine, in part, current inflation rates.

One of the constraints under which agents formulate their plans is the set of available information. For the purposes of estimation, it was assumed that information is constrained to a small set of aggregate macroeconomic variables, summarized by a low-order vector autoregression. For simulation purposes, however, it is possible to incorporate any of a number of assumptions regarding the availability of information and its subsequent gathering over time. Thus, users can simulate the model under VAR-based expectations, model-consistent expectations, or hybrid forms of expectations formation. In this paper, we shall utilize only model-consistent expectations. ${ }^{27}$

27. One might describe VAR-based expectations as reduced-rank rational expectations, or limitedinformation rational expectations. Consistent with this interpretation, Brayton and Tinsley (eds.) (1996) shows that for disturbances that arise from sectors represented by the VAR itself, such as random shocks to the federal funds rate, the dynamics of model responses under model consistent expectations and VAR-based expectations are quite similar. 


\section{Table 1 \\ Estimates of a Simple Monetary Policy Reaction Function (1981Q1 - 1999Q4)}

\begin{tabular}{|c|c|c|c|c|c|}
\hline \multicolumn{6}{|c|}{$R=\left(1-\alpha_{R 1}\right)\left(\tilde{\pi}+r r^{*}\right)+\alpha_{R 1} R_{t-1}+\alpha_{y 0} y_{t}+\alpha_{y 1} \Delta y_{t}+\alpha_{\pi}\left(\tilde{\pi}-\pi^{*}\right)$} \\
\hline Symbol --> & $\alpha_{R 1}$ & $\alpha_{y 0}$ & $\alpha_{y 1}$ & $\alpha_{\pi}$ & $\pi^{*}$ \\
\hline coefficient & 0.84 & 0.15 & 0.58 & 0.25 & 2.2 \\
\hline (standard error) & $(0.05)$ & $(0.05)$ & $(0.39)$ & $(0.09)$ & $(0.6)$ \\
\hline \multicolumn{3}{|c|}{$r r^{*}=2.5$ (assumed) } & \multicolumn{3}{|c|}{$\mathrm{SEE}=0.81$} \\
\hline \multicolumn{6}{|c|}{$\begin{array}{l}\text { Notes: } R \text { is the nominal federal funds rate (quarterly average basis); } \tilde{\pi} \text { is the four-quarter rate of } \\
\text { change of the (chain-weight) personal consumption deflator, } y \text { is output measured in percent } \\
\text { deviations from potential output; } r r^{*} \text { is the steady-state real interest rate (taken to be } 2.5 \text { per- } \\
\text { cent); and } \pi^{*} \text { is the target rate of inflation. Estimation is conducted using instrumental variables } \\
\text { with the lagged four-quarter inflation rate, two lags of the output gap, the lagged fed funds rate } \\
\text { and a constant as instruments. Potential output in FRB/US is constructed from split time trends } \\
\text { on the constituent parts of potential, including the participation rate, the labor force, the NAIRU } \\
\text { and trend total factor productivity. The steady-state real interest rate also comes from the FRB/ } \\
\text { US database and is consistent with approximately steady inflation and stable growth. }\end{array}$} \\
\hline
\end{tabular}

We now demonstrate the basic properties of FRB/US. To do this, we compare the properties of the model and those of the historical data using three methods: inflation and output autocorrelations, impulse responses to a shock to the federal funds rate equation, and the parameters of a dynamic IS curve equation. To begin, we need to characterize the behavior of monetary policy. To this end, we estimate a parsimonious interest-rate reaction function for the period from 1981Q1 to 1999Q4, arguably a single monetary policy regime. Table 1 shows the estimation results.

Like the Taylor $(1993,1994)$ rule, this rule is simple, but it adds some dynamic richness through the inclusion of two terms, one with the change in the output gap, and the other with the lagged federal funds rate. In comparison to the Taylor rule, which sets 
$\alpha_{y 0}=0.5, \alpha_{\pi}=0.5$ and all other $\alpha_{i}=0$, this rule is much more aggressive in its pursuit of the inflation target.

For the model-based analysis in this section, we assume policy follows this rule without error and that the inflation target is constant; we also assume the policy rule and the inflation target are known by the public with certainty. Figure 3 shows the autocorrelations of inflation, measured by the chain-weighted index of personal consumption expenditure prices, and the output gap. ${ }^{28}$ In both instances, the asymptotic model moments are represented by the dashed line and the moments estimated from the data are shown as the solid line. The dotted lines are one-standard-error bands for the data-based moments. ${ }^{29}$

The model- and data-based moments are computed using the data and equation residuals from the 1980s and 1990s. This sample period was chosen to approximate a single policy regime and to correspond with the estimated policy rule of Table 1.

As emphasized by Fuhrer and Moore (1995), inflation has been very persistent, historically, even during periods in which there were no apparent shifts in the inflation target. Owing to the generalized adjustment cost structure of wage and price adjustment, the FRB/US model also displays a significant amount of inflation persistence, albeit somewhat less than that evident in the data. ${ }^{30}$ However some of the persistence evident in the data is due to the large disinflation that occurred during the first few years of the sample. If the first two years are removed from the sample, the model and data autocovariances are nearly identical at the first four lags; nevertheless, at lags five through ten, the model still underpredicts inflation persistence.

28. Henceforth, the terms output and output gap will be used interchangeably to refer to the excess of aggregate demand over potential output measured in percentage points, just as noted in the text. Inflation shall refer to the rate of change of the chain-weighted personal consumption expenditure price index, either quarterly expressed at annual rates, or the four-quarter rate, as applicable, except as otherwise noted.

29. The model moments used here and below are computed from the formula for unconditional covariances. As such, the computed moments correspond to those that would be obtained from a stochastic simulation of infinite length.

30. See also the results reported in Brayton et al. (1997). 
Figure 3

Inflation and Output Persistence (Estimated Rule)

Inflation

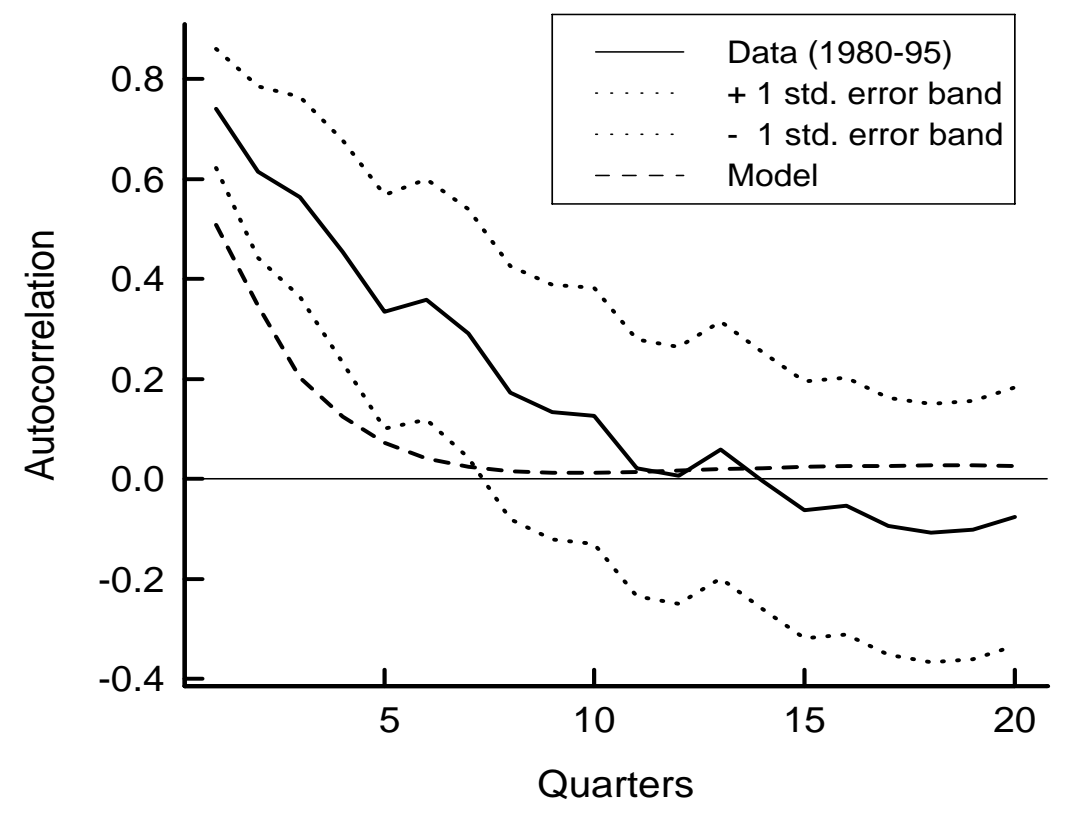

Output Gap

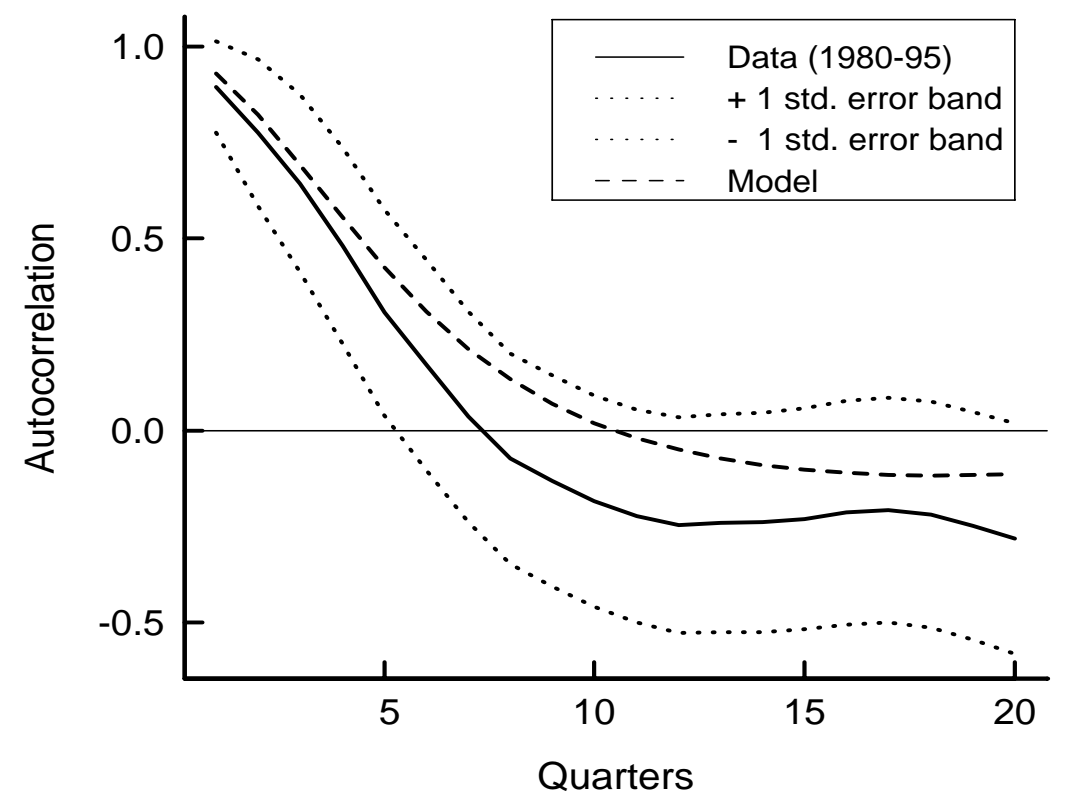


The model shows a great deal of persistence in the output gap. Sluggish adjustment of demand components, combined with persistence in the real interest rate driven by the propagation of movements in inflation, drive this result. In this case, autocorrelations from the model and from the data correspond closely.

This persistence in inflation and output is a common feature of structural macro models--both traditional and those incorporating rational expectations--as well as recent sticky-price general-equilibrium models such as those analyzed by Ireland (1997) and Rotemberg and Woodford (1997). The key distinction between the two classes of models is that the former achieve the bulk of this persistence though the inclusion of intrinsic inertia--that is, from lagged dependent variables--while generally maintaining the assumption of serially uncorrelated disturbances, while the latter are formulated under the assumption that there is little inherent inertia in inflation and spending, and it is the disturbances themselves that are serially correlated.

Now let us consider the impulse response from a disturbance to the estimated federal funds rate. Figure 4 shows the response of the funds rate, inflation, and the output gap. Also shown is the response from a VAR model estimated over the period from 1981Q1 to 1999Q1, together with one-standard-error bands. The figure shows that the magnitude and the general pattern of output and inflation in FRB/US are close to those of the data. 
Figure 4

Impulse Response to Funds Rate Shock

(100 basis points)
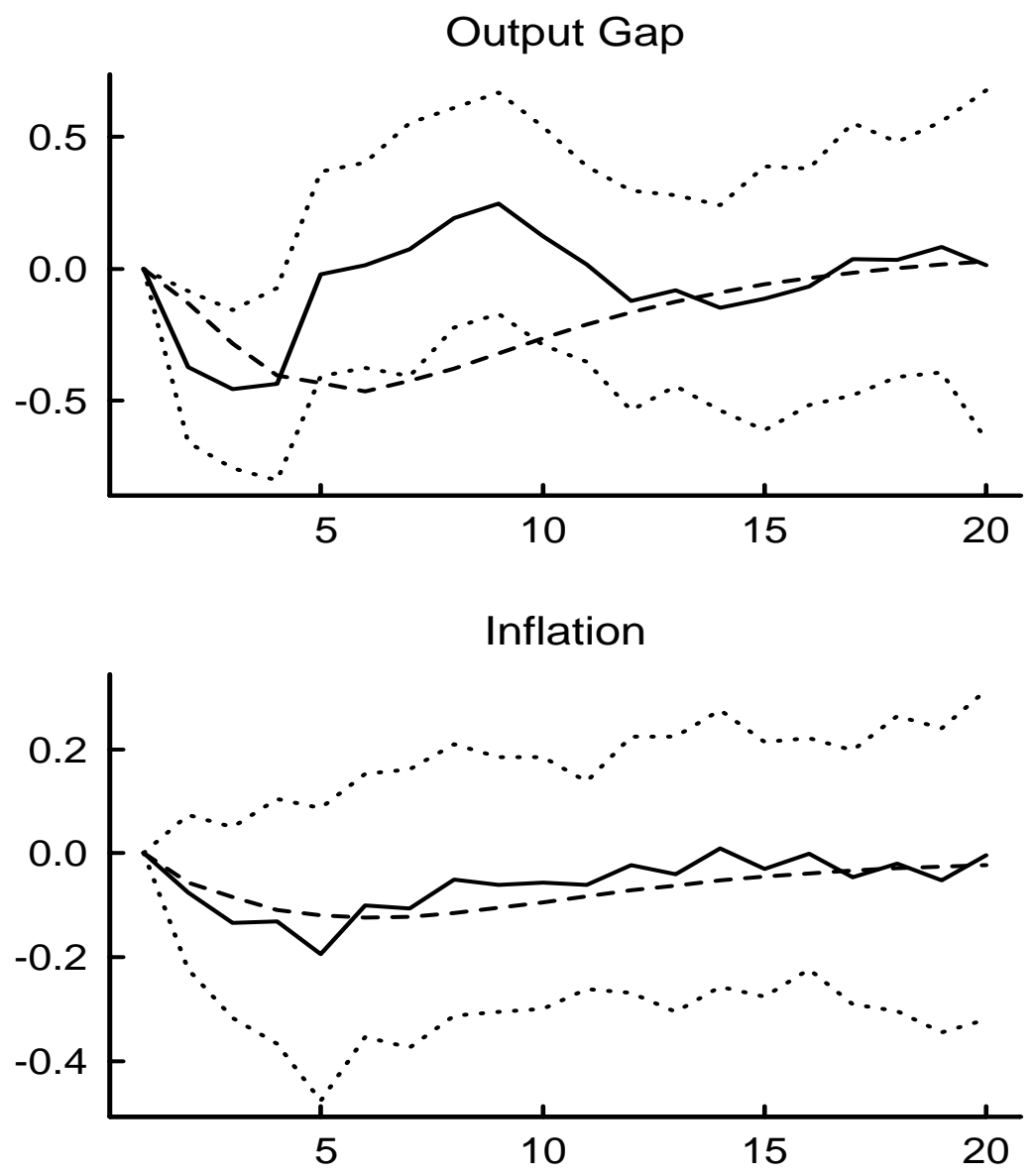

Funds Rate

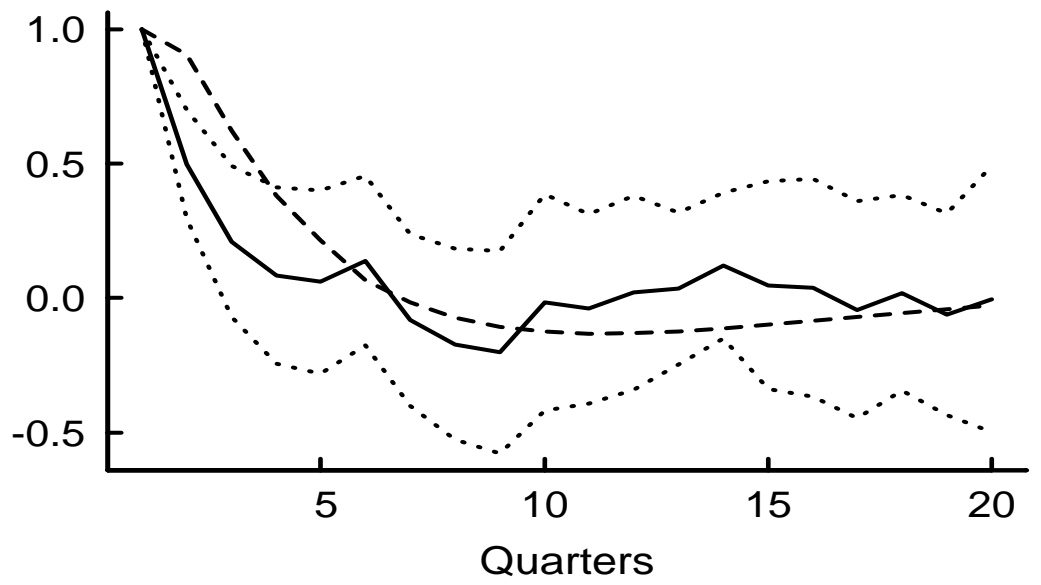

VAR model $\quad \cdots \cdots+1$ std. error band ..... - 1 std. error band 
Our final method for assessing the properties of FRB/US is to estimate a standard IS curve equation using model moments, and compare the model-generated estimates to those from the historical data. ${ }^{31}$ This approach is appealing in that differences between the model and the data are readily interpretable in terms of well-known macroeconomic concepts such as the interest sensitivity of aggregate demand, the magnitude of accelerator effects in aggregate demand, and so forth. Table 1 reports estimates of a simple dynamic IS equation. The specification of the IS equation is the same as in the Fuhrer-Moore model and is notable for its inclusion of output inertia, and the dependence of demand on the real long-term interest rate. We report estimation from the data for the longest sample for which data are reliable: 1966Q1 to 1999Q4. As seen in the table, the estimates from the model and those in the data are very similar, with the only significant difference being the higher interest-sensitivity of demand in the FRB/US model.

In sum, FRB/US is a relatively large structural rational expectations model that incorporates significant intrinsic inertia in inflation and real spending. The model fits the data well, both in terms of the individual equations and in terms of its system properties. The model's explicit disentanglement of intrinsic sources of dynamic propagation from expectational sources makes it well suited for the policy analysis experiments to which we shall turn shortly. However, before doing that, we need to discuss the numerical techniques employed to study this issue.

31. Of course, this procedure can also be applied to estimating Phillips curve equations, but there is little gain from doing so. Unlike the IS curve, inflation dynamics in the model are very sensitive to the specification of monetary policy. And over the period from 1980Q3 to 1997Q3, small sample problems plague the fit of estimated Phillips curves. 


\section{Table 2}

\section{Estimates of an IS Equation from Historical and Model Data (1966Q1 - 1999Q4)}

\begin{tabular}{|c|c|c|c|c|c|c|}
\hline \multicolumn{7}{|c|}{$\Delta y_{t}=\beta_{y 1} y_{t-1}+\beta_{y 2} \Delta y_{t-1}+\beta_{r 1} r r c b_{t-1}-\beta_{r 1} r r c b^{*}$} \\
\hline \multicolumn{2}{|c|}{ Symbol --> } & \multirow{2}{*}{$\frac{\beta_{y 1}}{-\mathbf{0 . 1 3}}$} & \multirow{2}{*}{$\frac{\beta_{y 2}}{\mathbf{0 . 2 5}}$} & \multirow{2}{*}{$\frac{\beta_{r 1}}{\mathbf{- 0 . 3 3}}$} & \multirow{2}{*}{$\frac{r r^{*}}{\mathbf{n} / \mathbf{a}}$} & \multirow{2}{*}{$\begin{array}{c}\text { SER } \\
0.94\end{array}$} \\
\hline Model & coefficient & & & & & \\
\hline \multirow[t]{2}{*}{ Data } & & & & & & \multirow[t]{2}{*}{0.76} \\
\hline & (std. error) & $(0.03)$ & $(0.08)$ & $(0.06)$ & $(0.28)$ & \\
\hline \multicolumn{7}{|c|}{$\begin{array}{l}\text { Notes: } r r c b \text { is the real return on } 30 \text {-year corporate bonds, discounted for coupon payments, with } \\
\text { expected inflation computed from a constrained VAR using methods described in Brayton and } \\
\text { Tinsley (eds.) (1996); and } r r c b^{*} \text { is the steady-state long-term real interest rate which is recov- } \\
\text { ered from the constant term and shown in the table column second from the right. See also the } \\
\text { Notes to Table } 1 .\end{array}$} \\
\hline
\end{tabular}

\section{Numerical Methods}

In all cases studied in this paper, we use a linearized version of FRB/US. Linearization serves two purposes. First, it ensures that all non-linear relationships that arise as endogenous phenomena of the experiments are easily isolated and quantified. Second, it simplifies computational burdens immensely. Since FRB/US is close to linear in the first place, and since the model's non-linearities have little to do with monetary policy issues, there is little cost in terms of accuracy from linearizing the model.

Setting aside the target bands, a linear rational expectations model can be written compactly in the following form:

$$
A_{1}\left[\begin{array}{c}
y_{t+1} \\
x_{t+1 \mid t}
\end{array}\right]=A_{0}\left[\begin{array}{c}
y_{t} \\
x
\end{array}\right]+\left[\begin{array}{c}
u_{t}^{y} \\
0
\end{array}\right]
$$

where $y_{t}$ is a vector of predeterimined variables, and $x_{t}$ is a vector of non-predetermined, or jump, variables. The first-order form of equations (7) can be constructed by compress- 
ing the lags longer than one in the original structure form model by creating artificial variables; that is by taking a second-order (or higher) equation, $C(L) y=c_{0}+c_{1} y_{t-1}+c_{2} y_{t-2}$ and defining $v_{t}=y_{t-1}$ and $v_{t-1}=y_{t-2}$ so as to create two first-order equations out of one second-order equation, and so on.

From equations (7), efficient computations can be done if a VAR representation of (7) can be constructed. In principle, this is straightforward enough, we need only find a matrix $A=A_{1}^{-1} A_{0}$ by premultiplying (7) by $A_{1}^{-1}$ :

$$
\left[\begin{array}{c}
y_{t+1} \\
x_{t+1 \mid t}
\end{array}\right]=A\left[\begin{array}{l}
y_{t} \\
x_{t}
\end{array}\right]+A_{1}^{-1}\left[\begin{array}{c}
u_{t}^{y} \\
0
\end{array}\right]
$$

Two problems come up in computing this state-space form of the model. The first is a numerical issue the possible singularity of the matrix $A_{1}$. Without a nonsingular $A_{1}$ matrix, the state-space representation of the model cannot be constructed, meaning that a recursive representation of the forward-looking model would not be possible. This is a common occurrence, particularly in large-scale rational expectations models. The model would then have to be solved using some iterative method, such as the extended path methods of Fair and Taylor (1983), or its stacked-time counterpart, Laffargue (1990). Given that we are interested in stochastic simulations of the model, the numerical cost of the using extended-path solution methods would be orders of magnitude more time consuming than a recursive method and would be subject to errors in measurement. Fortunately, the development in recent years of new methods of constructing state-space representations of linear forward-looking models obviates these complexities. For this paper, we employ a version of algorithm of Anderson and Moore (1985), updated in Anderson (1999), which uses a QR decomposition to find a nonsingular equivalent to the matrix $A$.

A second, related problem is the assurance of saddle-point stability of the model. Blanchard and Kahn (1980) outline the conditions that are necessary to assure saddle- 
point stability. These are that the number of roots of the matrix $A$ that are greater than unity equal the number of non-predetermined variables. Algebraically, different target rates of inflation are simply constant terms, so that if the model is saddle-point stable for one target rate of inflation, it is stable for all target rates. A test of the model confirmed that it is stable with 52 non-predetermined variables and 52 eigenvalues greater than unity.

While the model itself may be linear, the preceding discussion makes clear that the expectations mechanism for future targets is fundamentally non-linear. Even in the presence of this non-linearity, however, there is a way in which we can exploit linear on-line algorithms for solving models.

Given some initial $\pi_{t-1}^{*}$, a vector $E_{t-1}\left(\pi^{*}{ }_{t+i} \mid \pi^{*}{ }_{t-1}, \sigma, \bar{\pi}^{*}\right)$, a vector is computed outside of the model. Using a discrete approximation of the truncated normal distribution, this is possible because $E_{t-1} \pi^{*}{ }_{t+j}$ is independent of the state variables of the system. Then this non-linear path is approximated to arbitrary precision with a simple ARMA model, 'reverse engineering' the shocks necessary to replicate the non-linear $E_{t-1} \pi^{*}{ }_{t+j}$ at each date. The form of the equation stays the same at each iteration of the algorithm; however the historical shocks to the moving-average errors are changed depending on the initial value of $E_{t-1}\left(\pi^{*}{ }_{t} \mid \sigma, \bar{\pi}^{*}\right)$. An ARMA(1,25) model was chosen which means that specific values of the shocks can be chosen such that the linear ARMA model represents exactly the non-linearity up to $j=25$ and is approximately correct thereafter. In the state-space representation, each additional moving-average term adds an additional equation to the model, so there are trade-offs at work between speed and accuracy.

Some experimentation showed the $\operatorname{ARMA}(1,25)$ approximation to be a very good one. In terms of equations (8), the state matrix is augmented with variables for the target and its artificial ARMA determinants by adding a block of dimension 25. The "random shocks" to the target are then selected in such a way that they just so happen to give a nonlinear expected future path for the target. This works because once the form of the recur- 
sive system is determined any sequence of shocks can be supplied without having to bear the computational cost of resolving the model. Since the inherited target rate of inflation is known, the precise sequence of shocks consistent with the correct expected future path for the target can be fed in. The shocks necessary to generate the nonlinear forecast of $\pi_{t+i}{ }^{*}$ can be computed ahead of time, indexed against the initial $\pi_{t-1} *$ and stored in a grid, which also saves some computing time.

In short, we trick the linear algorithm to give non-linear forecasts with non-random shocks of a particular sequence.

Using this method, the time necessary to compute the simulations of 500 draws of 200 periods each described in Section 3 was approximately 32 minutes using one processor a Sparc Ultra 3000333 megahertz machine. A rough estimate of the computing time that would have been necessary to conduct the same exercise using non-linear extended path solution methods would be several weeks of continuous processing.

\section{Results}

Our results come from stochastic simulations of the FRB/US model. Each experiment in comprised by 500 simulations of 200 periods each. After discarding the first 20 observations, we are left with 500 replications times 180 periods or 90,000 observations per experiment. In most instances, we take the standard deviation of innovations to the target to be 0.25 percent. This is the standard deviation of innovations to the Federal Reserve Bank of Philadelphia's survey of expectations of inflation of 10 years ahead; expectations of inflation this far into the future can be reasonably taken to be solely a monetary phenomenon and thus a measure of private agents' expectations of the target rate of inflation. This standard deviation is also close to standard deviation of changes in the implied target rate of inflation shown in Figure 1, for the period since Alan Greenspan assumed the chairmanship of the Federal Reserve in $1987 .{ }^{32}$ The width of the bands is \pm 1 percentage point, except as noted. 
For most of these simulations, monetary policy is governed by equation (2), without error. Thus, at the beginning of each period, agents can infer $\pi^{*}{ }_{t-1}$ from last period's federal funds rate setting. Agents then form an expectation of the future path of the target using equations (4) and (5), or (4) and (6), as applicable.

\subsection{Model properties with target bands}

Figure 5 shows the mapping of inflation against the target rate of inflation from our stochastic simulations. (Ignore the dotted lines for the moment.) Two cases are shown. The dashed line is the mapping of inflation against the target when the target follows a pure random walk. This mapping, which is labeled $g_{r w}\left(\pi^{*}\right)$, is diagonal: the relationship, on average, between inflation and its target, is one-for-one when the target follows a pure random walk.

Now consider the solid line. Notice that it has roughly s-shaped. It is, moreover, flatter than $g_{r w}$, meaning that the range for actual average inflation is less than the range for target inflation. Let us designate this mapping $g\left(\pi^{*}\right)=E_{t-1} \pi\left(\pi^{*} \mid \bar{\pi}^{*}, \sigma\right)$ where the right-hand side of the equality notes that this is the expected value of the mapping of inflation on target inflation, conditional on the location of the upper (and lower) bound, and on the size of innovations to the target. ${ }^{33}$

Notice as well that while the bands are between plus-and-minus one percentage point, the target never actually reaches the edge of the band. For this to happen, one would have to draw exactly the right shock to reach the edge of the band; and the probability of

any one particular value is vanishingly small. ${ }^{34}$ Comparing this line with the mapping for

32. It is considerably smaller than innovations in the implicit target rate of inflation for the whole period, even if one omits the discrete shift in the early 1980s from the data. Thus, the magnitude of innovations used here appears to be a reasonable one.

33. Figure 5 and all subsequent figures are constructed by sorting and ordering observations of $\pi^{*}$ from $\pi^{*}$ to $\bar{\pi}^{*}$, gathering the corresponding observations of $\pi, y, r r$ and so forth. The matrix of sorted observations is then group into cells of identical widths and average across the values of each cell. It is these averages for the cells that are shown in the graphs.

34. This is a manifestation of our using reflecting barriers. Absorbing barriers would reach the boundary with some probability mass. 
our unbounded process shows the influence of the credible target band: as $\pi^{*}$ gets up close to $\bar{\pi}^{*}$ (down close to $\underline{\pi}^{*}$ ), inflation itself falls below (rises above) the current $\pi^{*}$, on average. The extent to which this occurs is a function of the curvature of expected future target values. In the present case, at the upper end of the curve, where the target rate of inflation is nearing the upper bound, the four-quarter inflation rate averages about 0.55 percent, or more than four-tenths below the target inflation rate. By contrast, when $\pi^{*}$ is close to the midpoint, $g\left(\pi^{*}\right)$ is very close to the linear mapping of the pure random walk case. This outcome illustrates that the establishment of target bands for inflation gives rise to what the exchange-rate target-band literature calls the honeymoon effect: the promise of fidelity in constraining drift in the target rate of inflation variability is rewarded by restraint in the range of the average inflation rate. ${ }^{35}$ As we describe in detail below, this operates through expectations of future target inflation rates impinging on current priceand wage-setting decisions.

The two dotted lines on Figure 5 are the one-standard-error bands for inflation in an economy where there are only shocks to the target rate of inflation. The widths of these bands are not particularly important per se, since the real world is subject to a much wider variety of shocks. What is interesting is the curvature of the confidence bands and their narrowing as the boundaries for the inflation target are approached. What this narrowing indicates is the smaller range of probabilities for future target rates of inflation when the current target is at the edge of the band. Recall that if the inherited rate of inflation were to reach the edge of the band, fully one half of the distribution of target rates one step ahead would be truncated, reducing the range of future target rates of inflation.

35. See, e.g., Krugman (1991). 
Figure 5

\section{Inflation versus Inflation Target (shocks to the target only)}

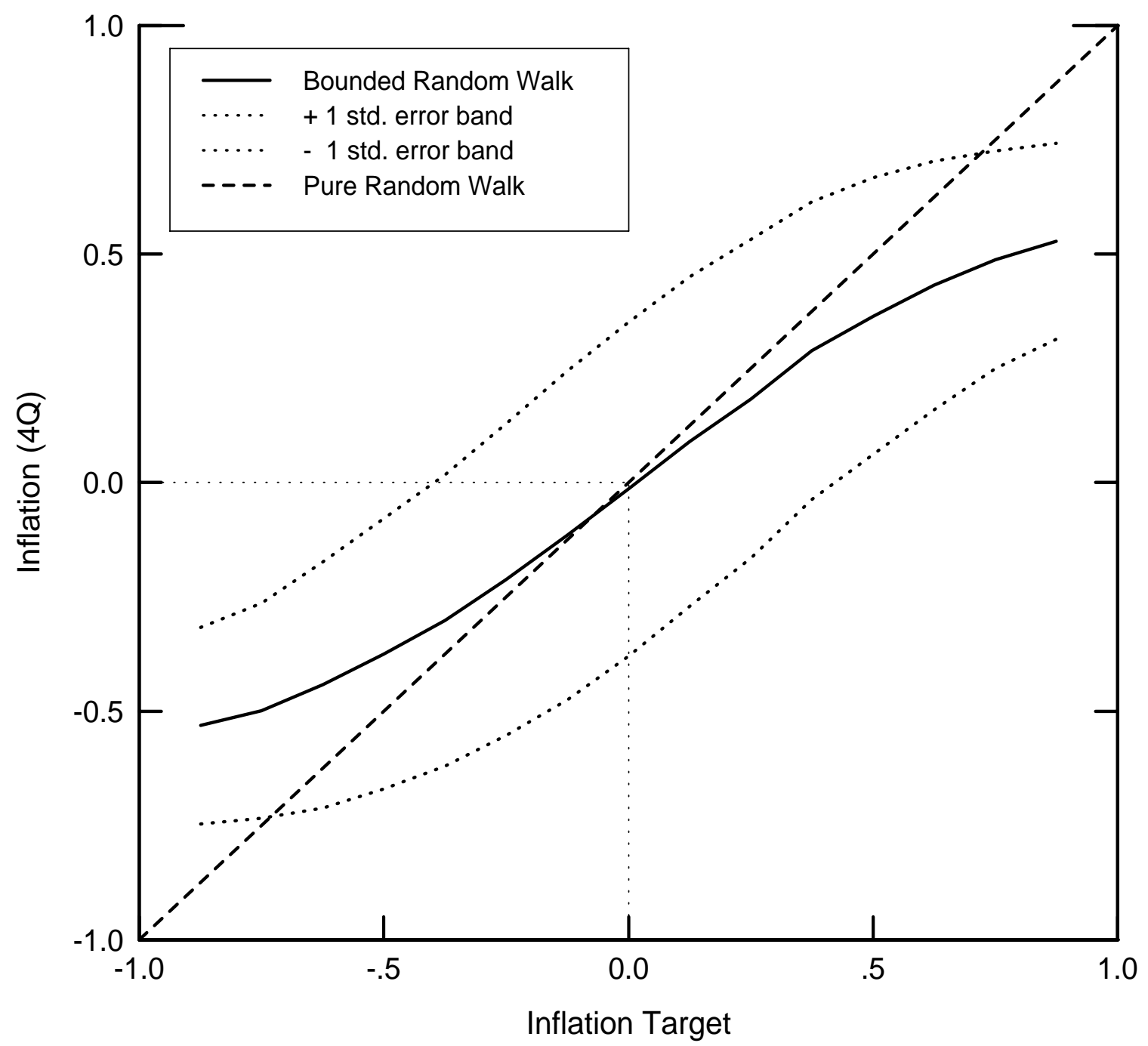

We have established that credible inflation target bands can constrain the range of inflation outcomes, relative to a pure random walk. We now examine some general equilibrium aspects of policy design with credible inflation target bands. To do this, we need to consider a wider range of variables, which we can do with the aid of Figure 6.

Before explaining the economics behind the lines in Figure 6, let us first just describe what the four quadrants represent. The upper-right quadrant of this four-quadrant 
diagram shows $g\left(\pi^{*} \mid \bar{\pi}^{*}=1\right)$ and so merely repeats Figure 5--except without the error bands. Moving to the upper-left quadrant, we have the mapping of inflation on the output gap. This is not the slope of a Phillips curve as such; rather it is the (mean of the) stochastic relationship between the target inflation rate and the actual inflation rate. The bottomleft quadrant shows the mapping of output and the real federal funds rate, both measured in deviations from steady-state levels. Finally, the bottom-right quadrant completes our macroeconomic tour with the mapping of the real federal funds rate against the target rate of inflation. This four-quadrant graph portrayal allow us to trace the average levels of four variables at once, as illustrated by the two cases marked by the dotted lines.

Now let us walk through the economics of Figure 6. Our base case is shown as the thin solid line with the case where the target follows a pure random walk being designated by the dashed line. We begin with point A on the base-case mapping $g\left(\pi^{*}\right)$ in the upperright quadrant. At this point, $E_{t-1}\left(\pi_{t} \mid \pi_{t}^{*}\right)<\pi_{t}^{*}$ because private agents know that the target is more likely to fall than rise in the future. Because firms find it costly to adjust prices and wages, firms must plan ahead to minimize costs and so this expectation influences their price- and wage-setting behavior today, and thereby affects realized inflation today. 
Figure 6

Summary of Macroeconomic Outcomes

(random walk versus inflation target bands)

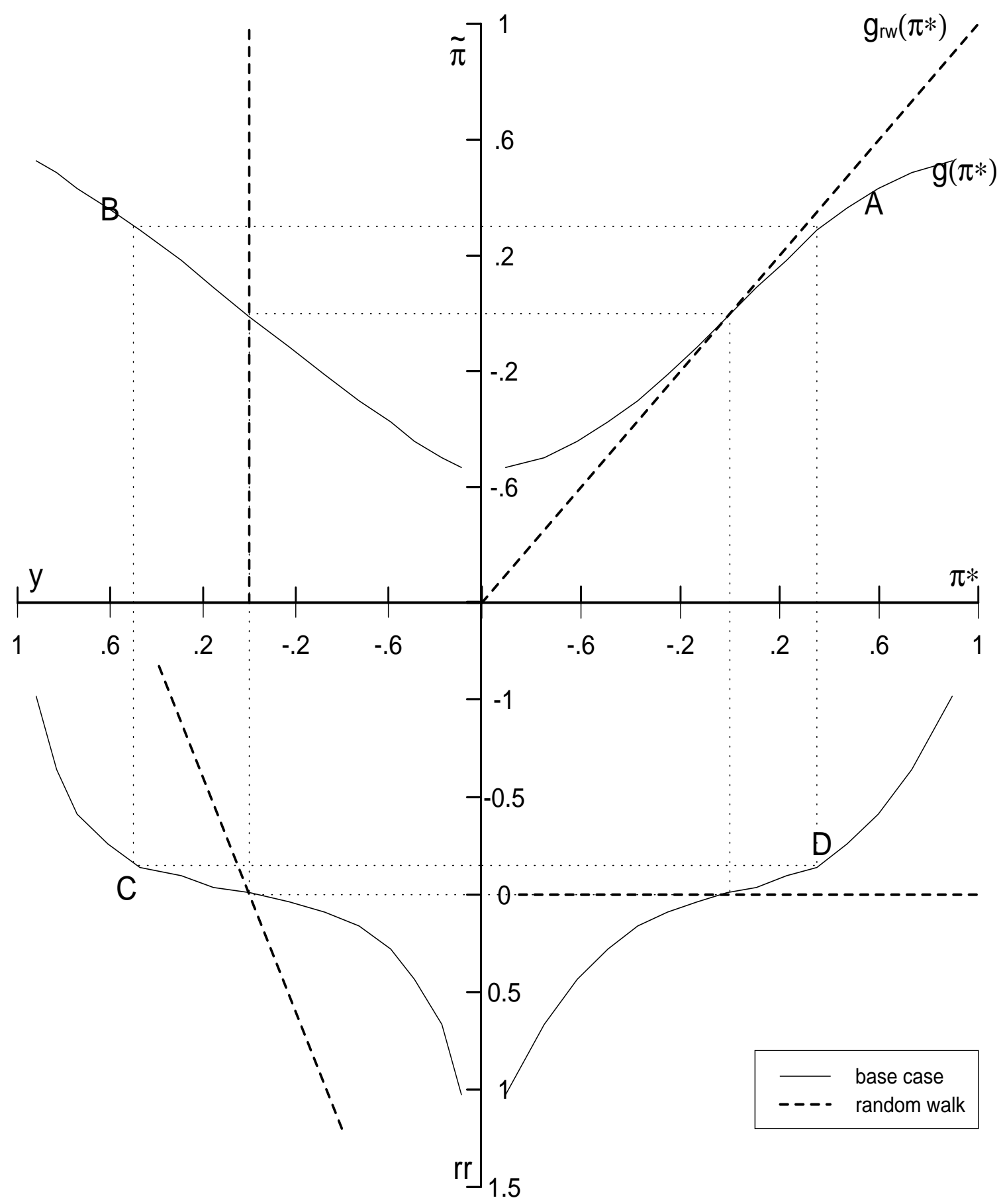

5. Results 
Moving along the dotted line to point B in the upper-left quadrant we see that point A corresponds with an output gap that is positive, on average. We see that the relationship between the average level of output and inflation is positively sloped and linear in the base case, while in the random-walk case, there is no output gain to be had from allowing drift in the target. The random-walk case is simply an outcome of the superneutrality of the model: there is no trade-off between output and inflation and thus no slope of the dashed line in the upper-left quadrant. For the base-case solution, the 'bias' in inflation expectations relative to the current target rate of inflation means that output can be positive because inflation is expected to fall in the future. ${ }^{36}$ To see why this is so, we need to move to the lower-left quadrant.

In the lower-left quadrant, we observe a negative relationship between the output gap and the average level of the real interest rate. Notice that at point $\mathrm{C}$, the real federal funds rate is slightly negative even though output is substantially positive. This is feasible because the "bias" in expected inflation--which carries a large weight of 3 in the policy rule--offsets the positive output gap. To put the same idea a different way, the lower expected future inflation rate at point A means that there can be a lower real interest rate at the corresponding point $\mathrm{C}$, which supports higher output at point $\mathrm{B}$.

Note that the curved line for the base-case model implies that the quasi-steadystate interest elasticity changes non-linearly with the target rate of inflation. The shape of the curve comes from the cumulative normal distribution. In the random walk case, it is constant. ${ }^{37}$ Roughly the same shape is witnessed in the top-right quadrant showing the

\footnotetext{
36. It is also useful to think of this from the monetary authority's point of view. The authority is attempting to moving inflation to the current-period target shown at point A. But because the expected future target is lower than the current target, current inflation is lower than the current target, on average. By contrast, in the random-walk case, inflation, on average, will be at the target value. This means that policy will be easier at target rates of inflation like point A with bands than it would be when the target follows a random walk. This we see in point $C$ in the lower-left quadrant. The easier policy, in turn implies an average positive output gap as shown by point B in the upperleft quadrant.

37. We show the interest elasticity of aggregate demand in the random walk case to be the -0.33 value computed in Table 1.
} 
mapping between inflation and target inflation, except that the curve is stretched out in this instance. This is a manifestation of the supply shocks of the model. The lower the proportion of shocks to the supply side of the model, the more of the shape of the cumulative normal distribution is retained and the larger the honeymoon effect.

Finally, moving to point $\mathrm{D}$ in the lower-right quadrant, we are reminded that the real interest rate is generally negatively related the target rate of inflation. In the pure random walk case, the horizontal dashed line shows that there is no relationship, on average, between the target rate of inflation and the real interest rate. At point $\mathrm{D}$, the real interest rate is lower than it would be if agents did not believe the target was bounded. The expectation of a lower target rate of inflation in the future allows the current real interest rate to be lower than it otherwise would be, thereby supporting higher output than usual.

In sum, we see that the implications for the monetary authority of credible target bands for inflation are (i) a narrower range of inflation for a given range of the inflation target; (ii) a positive range of output, meaning that there exists a trade-off between output and inflation, (although it cannot be said that this is a long-run trade-off); and (iii) a range for real interest rates.

\subsection{Quantitative performance}

The choice of target band limits of plus-or-minus one was an arbitrary one. To explore the implications of alternative assumptions, Table 3 shows the effect on aggregate (unconditional) volatility of alternative choices. The statistics are based on stochastic simulations using the full set of stochastic shocks and pooling over all simulated observations. The first column in the body of the table corresponds to a credible fixed target rate of inflation, the usual assumption undertaken in assessments of policy rules. The last column cov- 
ers the pure random walk case. In that case, the values of many simulated variables are unbounded and shown as "n/a".38.

\section{Table 3}

Simulated Standard Deviations of Target Band Regimes

\begin{tabular}{|c|c|c|c|c|c|}
\hline \multirow[b]{2}{*}{ Column no. --> } & \multirow[b]{2}{*}{ (1) } & \multicolumn{3}{|c|}{ Bound on inflation target } & \multirow[b]{2}{*}{ (5) } \\
\hline & & (2) & (3) & (4) & \\
\hline $\begin{array}{c}\text { Endogenous } \\
\text { variable }\end{array}$ & $\left|\bar{\pi}^{*}\right|=0$ & $\left|\bar{\pi}^{*}\right|=0.5$ & $\left|\bar{\pi}^{*}\right|=1.0$ & $\left|\bar{\pi}^{*}\right|=1.5$ & $\left|\bar{\pi}^{*}\right|=\infty$ \\
\hline$R$ & 2.76 & 2.87 & 3.01 & 3.11 & $\mathbf{n} / \mathbf{a}$ \\
\hline$y$ & 2.70 & 2.74 & 2.90 & 2.98 & 3.10 \\
\hline$\tilde{\pi}$ & 0.88 & 0.93 & 1.04 & 1.21 & $\mathbf{n} / \mathbf{a}$ \\
\hline
\end{tabular}

Note: $R$ is the nominal federal funds rate measured on a quarterly average basis, $y$ is the output gap, measured in terms of percent deviations from potential output; $\tilde{\pi}$ is the four-quarter inflation rate; i.e., $\tilde{\pi}=\sum_{i=0}^{3} \pi_{t-i} / 4$; Numbers in the first three rows of the body of the table are standard deviations computed from pooling 500 draws of 180 periods each, after discarding twenty observations per draw to account for initial conditions. In all cases 51 stochastic shocks are drawn using the variance-covariance matrix of the period from 1981Q1 to 1995Q4.

The most remarkable observation from Table 3 is how unremarkable the differences are: tighter target band limits improve performance of the economy measured in terms of the unconditional standard deviation of output, inflation and the funds rate, but not by a great deal.

At the outset of this paper, we noted that among the devices through which inflation targeting countries attempt to commit to constraining their discretion are ranges for

38. In this case the range is for consumer price inflation as measured by the four-quarter growth rate in the chain-weight personal consumption expenditure price index. All the countries that have announced specific targets for inflation have named a 12-month rate of some consumer or retail price index as the target variable. The FRB/US model does not have a CPI and is quarterly model. Thus, we use the growth rate of the four-quarter PCE price index here. 
inflation (as opposed to bands for target inflation). ${ }^{39}$ In Table 4 we examine some aspects of the efficacy of ranges for inflation as a device for containing discretion, or policy drift, by looking at the likelihood of inflation rate departing from selected ranges. These ranges, denoted by $\bar{\pi}$ and $\underline{\pi}$, are shown down the first column of the table. Observe that they refer to ranges for inflation itself. We examine three ranges for inflation-- $\tilde{\pi}$, without the asterisk but with a tilda overstrike to indicate that it is the four-quarter rate--measured in terms of deviations from the steady-state rate of zero. ${ }^{40}$ To keep the syntax clear, we shall refer to desired variability of inflation itself as ranges, and limits on the inflation target as bands. An examination of this sort gives an idea of the extent to which commitment to a range of inflation (an observable variable) can stand in for commitment to a band width on target inflation (an unobservable).

Across the top of the table we show widths for the band for target inflation. Down the left-hand column of the table is shown three ranges for inflation variability. The body of the table shows, therefore, the bands on inflation targets that would have to be kept to in order to deliver the performance on four-quarter inflation ranges that are shown. Performance in this regard is shown in two dimensions, the likelihood of being outside the inflation range shown at left measured in terms of the proportion of quarters outside the range, and the duration of the average range violation in quarters. As a concrete example, the first row of column (1) of the table shows that with no variability of the inflation target at all, inflation will depart from a range for inflation of plus-or-minus 2 percentage points about 3 percent of time. The 2.1 number immediately below says that these departures tend to

39. It is interesting in this regard to note the motivation for ranges for inflation as given by John Crow, then Governor of the Bank of Canada (1991): "The purpose of setting out formal targets is to provide a clear indication of the downward path for inflation over the medium term so that firms and individuals can take this into account in their economic decision-making... [If people] base their economic decisions on this declining path for inflation, the objectives can be readily achieved and will contribute to lower interest rates. The inflation targets also provide information... [that] should provide a better basis than before for judging the performance of monetary policy" (Bank of Canada, 1991, p. 11).

40. Those countries that explicitly target inflation measure performance in terms of some 12-month rate of change in prices. We use the quarterly counterpart to that calculation here. 
last only about six months. The last row of the same column shows that even with a fixed target rate of inflation--and central bank preferences that weight inflation control fairly highly--the authority should not expect to keep inflation within plus-or-minus one percentage point of the target more than about 70 percent of the time.

\section{Table 4}

\section{Likelihood and Duration of Inflation Target Range Violations}

\section{Bound on inflation target}

Column number -->

(1)

(2)

(3)

(4)

(5)

\begin{tabular}{|c|c|c|c|c|c|c|}
\hline \multicolumn{2}{|c|}{ Inflation range } & \multicolumn{5}{|c|}{$\left|\bar{\pi}^{*}\right|=0 \quad\left|\bar{\pi}^{*}\right|=0.5 \quad\left|\bar{\pi}^{*}\right|=1.0 \quad\left|\bar{\pi}^{*}\right|=1.5 \quad\left|\bar{\pi}^{*}\right|=\infty$} \\
\hline \multirow{2}{*}{$|\bar{\pi}|=2.0$} & likelihood & $\mathbf{0 . 0 3}$ & 0.03 & 0.05 & $\mathbf{0 . 1 0}$ & 0.45 \\
\hline & duration & 2.1 & 2.2 & 2.5 & 3.0 & $\mathbf{n} / \mathbf{a}$ \\
\hline \multirow{2}{*}{$|\bar{\pi}|=1.5$} & likelihood & 0.10 & 0.11 & 0.15 & 0.22 & 0.57 \\
\hline & duration & 2.6 & 2.6 & 3.0 & 3.8 & $\mathbf{n} / \mathbf{a}$ \\
\hline \multirow{2}{*}{$|\bar{\pi}|=1.0$} & likelihood & 0.28 & 0.28 & $\mathbf{0 . 3 4}$ & $\mathbf{0 . 4 3}$ & $\mathbf{0 . 7 0}$ \\
\hline & duration & 3.2 & 3.3 & 3.9 & 4.9 & $\mathbf{n} / \mathbf{a}$ \\
\hline
\end{tabular}

Note: 'likelihood' is the average proportion of quarters in which $\tilde{\pi}$ exceeded the absolute value of the range for inflation, measured relative to the long-run target, $\pi^{\dagger}$. 'Duration' is the average length of time $\tilde{\pi}$ spends outside of the range, once a violation is recorded. Computations come from averages across the 500 draws for 180 dates in each draw. See also the notes to Table 3.

Reading the table from right to left across any given row shows that as the range of target inflation rates is narrowed, the likelihood and duration of inflation ranges diminishes. This much is hardly surprising. A more interesting observation is that there are sharply diminishing returns, regardless of the width of the inflation range. For example, for an announced inflation range of plus-or-minus 1-1/2 percentage points (the third row), 
cutting the target band width from plus-or-minus 1 percentage point (column 3 ) to 1/2 percentage point (column 2) reduces the frequency of violations from 0.15 to 0.11 . A further cut of the target band width to zero (column 1) reduces the frequency only a trivial amount.

In general, there is a noteworthy frequency of range violations for all target band widths and for most inflation ranges: To get the likelihood of range violations below ten percent one must accept very wide inflation ranges of plus-or-minus 2 percentage points. Economically speaking, ranges this wide have little meaning for an economy like the United States. Focusing on ranges for inflation of plus-or-minus 1 percentage point--that is, on the range that most inflation-targeting countries use--we see a substantial likelihood of violations, and departures usually last more than 3 quarters when they occur. More than anything else, this reflects the fact that a substantial portion of the variability of inflation comes from shocks to the wage-and-price block of the model. There is little that the monetary authority can do to offset such shocks. Blackburn and Christensen (1989) emphasize that monetary policy credibility comes from a combination of the willingness of the monetary authority to pursue its inflation objective, and the ability of the authority to achieve the objective. Table 4 suggests that there are limits to what the Fed can expect to deliver in terms of outcomes of monetary policy, even if bounds on inflation targets are specified, kept, and believed. On the positive side, however, the table also shows that reductions in the width of the inflation target bands below plus-or-minus one-half percentage point yield very little in terms of the frequency of range violations, regardless of the range selected. 41

41. There is also the prospect, alluded to by Chairman Greenspan in the quote at the beginning of this paper, that some of the 'exogenous shocks' to the model's wage-price blocks might be expectations scares brought about by low credibility, on average, through history. This would be the case, for example, if policy control were so languid as to induce sunspot equilibria; see, Chari et al. (1999) and Clarida et al. (1998). To the extent that this is true, the variance of these "supply shocks" will be lower in the future than in the past, the honeymoon effect of Figure 5 will be larger, and the probability of inflation range violations will be lower than what is shown in Table 4.

5. Results 


\subsection{Comparative statics}

The unconditional standard deviations shown in Table 3 mask some considerable variation in the conditional statistics. Figure 7 replicates Figure 5 in showing the mapping from the inflation target to inflation, this time for target band limits of plus-or-minus onehalf percentage point (the thick line) together with our base-case assumption of plus-orminus one percentage point (the thin line). The differences here are much more pronounced than Table 4 might have led one to believe; the honeymoon effect is apparent and substantial at all ranges of $\pi^{*} \neq 0$, not just beyond the first couple of tenths of a percentage points away from the midpoint of the range. Even in the presence of the unconditional inflation variability of 0.93 (Table 3 , third row, column 2), this is an economically important difference in performance.

Just as we reduced the bandwidth from 1 percentage point to one-half point in Figure 7, we could have gone the other direction and increased it. Doing so produces a flattening of $g\left(\pi^{*}\right)$, and a region near the midpoint of the bands in which $g\left(\pi^{*}\right)$ and $g_{r w}$ lie on top of one another. In this region, average inflation performance with a credible (but wide) band and a pure random walk would be no different. An implication of this is that good performance in controlling drift in inflation targeting does not necessarily guarantee a honeymoon effect if this performance is not recognized by private agents as credible. This observation goes some way in explaining why countries that target inflation expend so much time and effort in communicating to the public the intentions of policy. ${ }^{42}$ They hope to reverse the usual causal order of good targeting performance leading to enhanced reputation and higher credibility by instilling credibility with words and thereby making the promised improved performance easier to achieve. ${ }^{43}$

42. All of the five countries identified in Siklos (1997, pp. 132-133 as formal inflation targeters-Canada, Finland, New Zealand, Sweden and the United Kingdom--produce (or did produce) an inflation report of some kind on a regular basis. (Finland is now a member of the European Union.) 
The other parameter that affects the honeymoon effect, is the magnitude of innovations to the target rate of inflation. In our base case, the assumed standard deviation of disturbances to $\pi^{*}$ is 0.25 percentage points, a magnitude that is consistent with historical experience. Figure 8 shows the implications of higher variability in the monetary authority's target, holding constant the target band width at plus-or-minus one percentage point.

As discussed above, a larger $\sigma$ implies a more substantial non-linearity in expected future target values for any initial $\pi^{*} \neq 0$. Not surprisingly, therefore, Figure 8 shows $g\left(\pi^{*} \mid \sigma=0.5\right)$ to be flatter than in the base case. With the larger $\sigma$, there is a honeymoon effect even with relatively wide target bands. This shows that a monetary authority with erratic preferences has considerably more to gain from the establishment of target band widths, if such an authority can secure credibility. It also may help explain why those countries that have adopted inflation targets with bands have done so after abandoning under duress an exchange-rate targeting regime, while those countries that have announced imprecise inflation-targeting objectives do not have a record of such difficulties. $^{44}$

43. That inflation targeting with bands is an attempt to get a 'free lunch' along the lines described in the text is made clear for the case of Canada by Freedman (1995, p. 27): "These ranges were in fact smaller than were called for in empirical work done at the Bank. There is a trade-off...[t]he wider are the bands, the higher is the probability of successful achievement of the targets but the less useful are the targets in changing behavior. In the end, we decided to use somewhat narrower bands to avoid the problem that overly wide bands might leave the impression that the authorities were not serious about bringing inflation down."

44. Canada is the only country whose decision to adopt a well defined inflation targeting regime was not prompted by a crisis. In most cases, inflation targeting countries had previously failed to maintain an exchange-rate targeting regime. 
Figure 7

Inflation versus Inflation Target

(selected band widths)

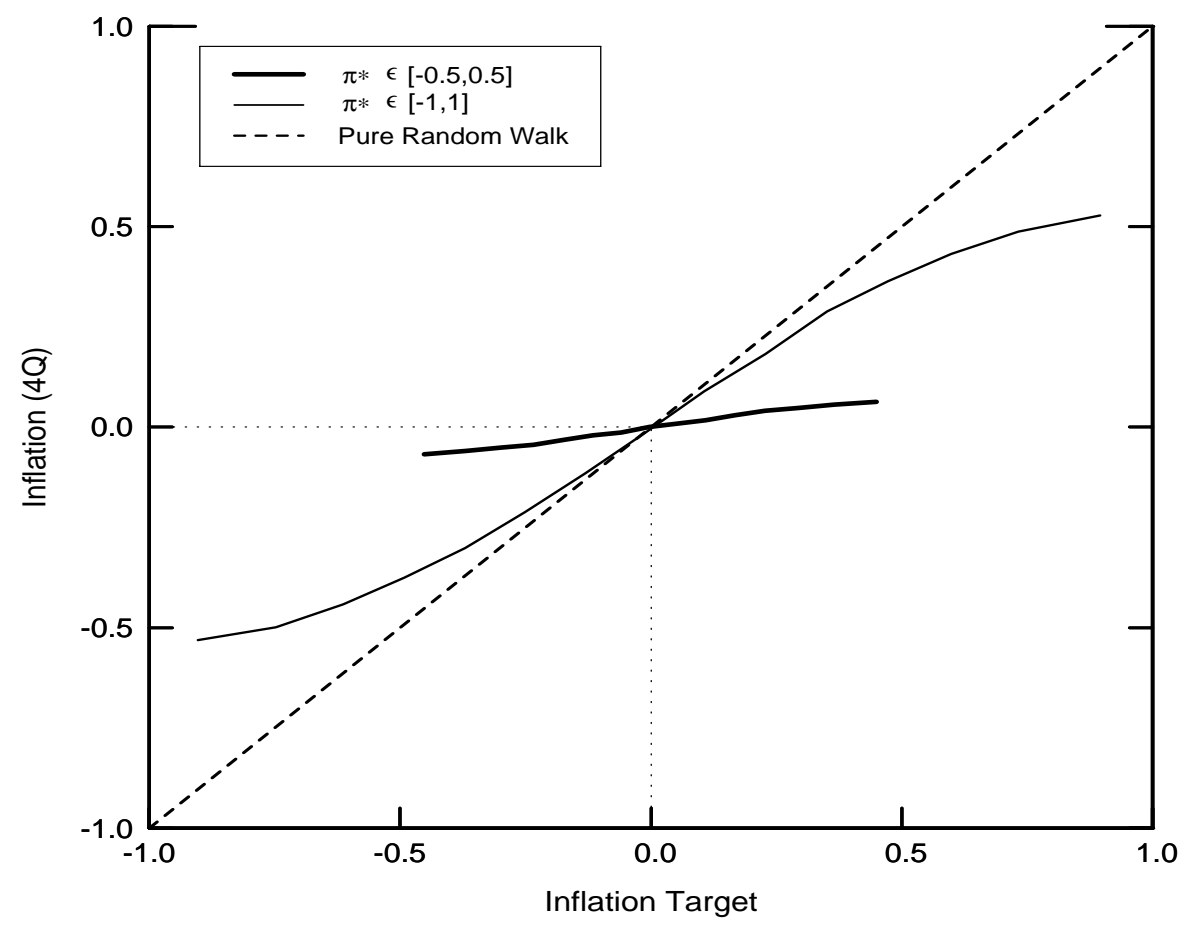

Figure 8

Inflation versus Inflation Target

(selected standard deviations of target shocks)

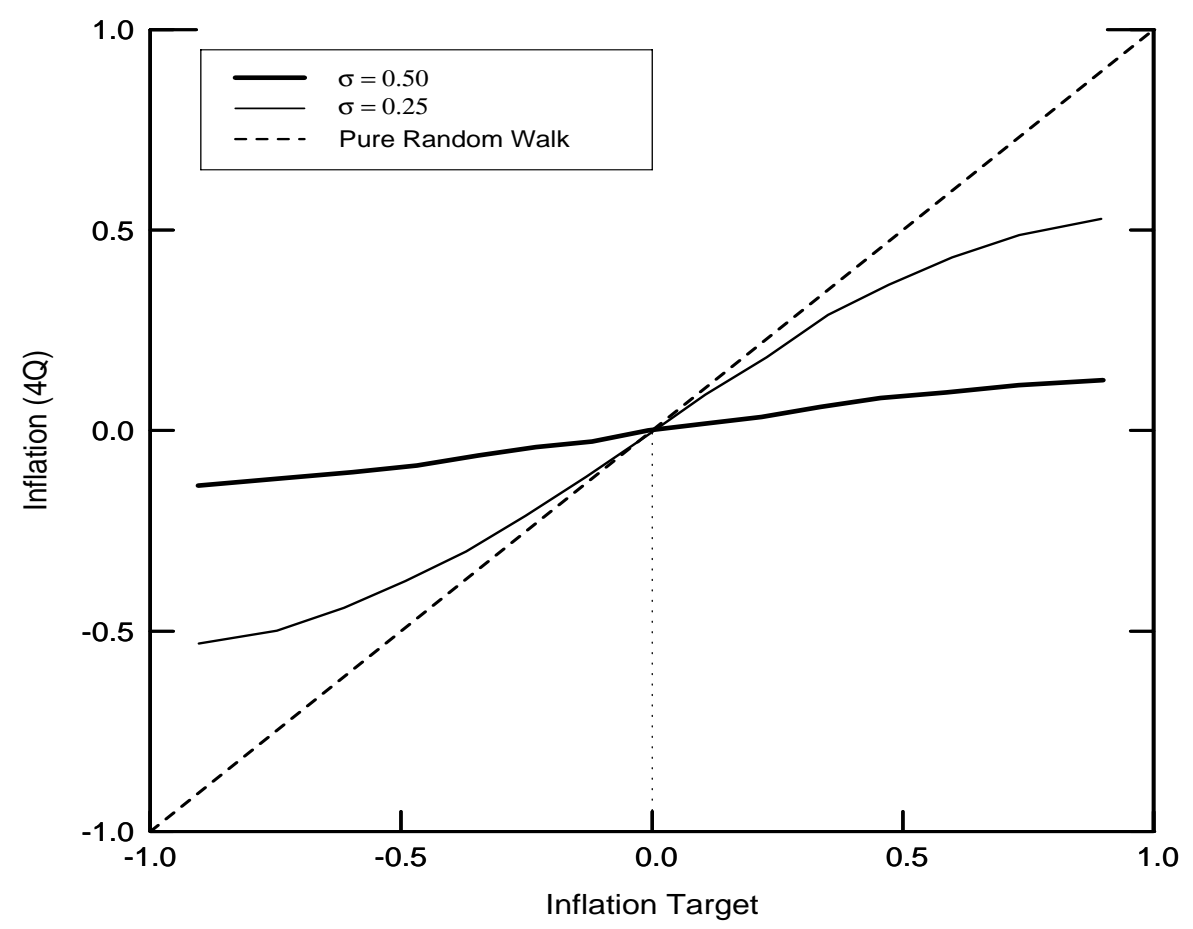

5. Results 


\subsection{Alternative policies}

Let us now compare our bases-case results with those of a few selected alternatives, beginning with a 'less hawkish' policy. Recall that for our base case, we assumed that the monetary authority placed three times the importance on inflation stabilization as on output stabilization. We now consider a policy rule derived with the opposite loss function weights: 0.75 on output and 0.25 on inflation. This raises the coefficient on the output gap of 0.9 in our base-case rule to about 1.1, and lowers the coefficient the twelve-quarter moving average of inflation from 3 to approximately 0.75 . It is worth emphasizing that this new rule is on the same efficient policy frontier as the base-case one.

The thin lines in Figure 9 are the same lines as in Figure 6; they represent our base case. The thick lines are computed in exactly the same way as the thin lines, except using the coefficients of the less hawkish rule. Starting, once again, in the upper-right quadrant, we see that $g_{l h}\left(\pi^{*}\right)$ is flatter than it is in the base case. This means that there is a larger honeymoon effect, or to put the same point a different way, there is less variability in inflation for a given degree of variability in the target than in the base case. In the upper-left quadrant, we see a steeper relationship between the average level of output and inflation and, more importantly, a much narrower range of output gaps is implied by that relationship. In the lower-left quadrant we see that the range of real interest rates associated with these output gaps is not only smaller, a slight backward bend appears: a decline in the output gap, beginning from zero, arising from a decline in the target which is accompanied by a smaller decline in inflation, results in a (very small) decline in the real interest rate. 
Figure 9

Implication of Different Policy Preferences Under Inflation Target Bands

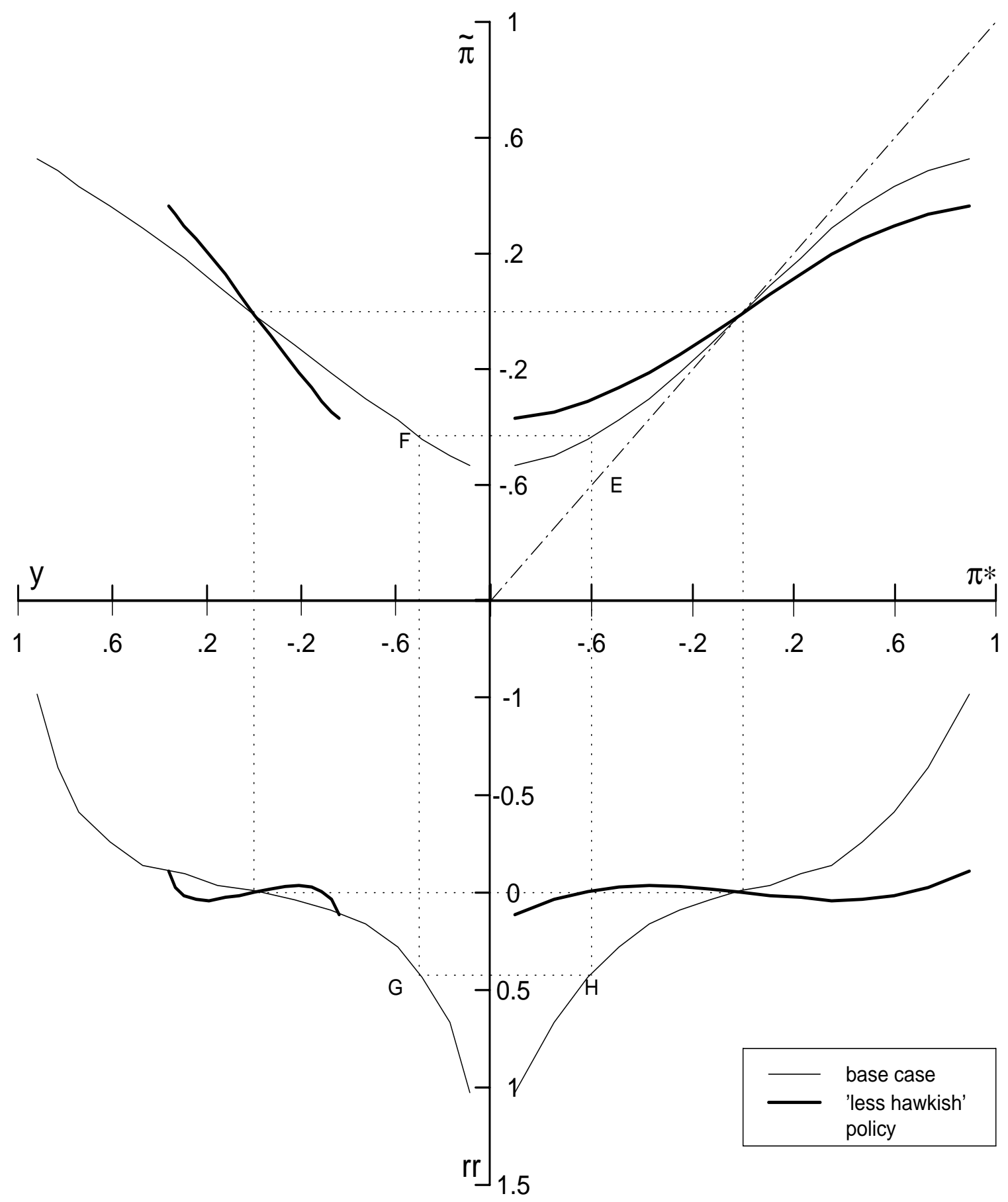

5. Results 
The quantitative assessment of this rule is shown in Table 5 below. Each column in the body of the table records aspects of the performance of a particular policy rule; the first column shows the performance of our base-case rule. Column (2) shows the performance of the 'less hawkish' rule. (We will ignore column (3) for now.) The first panel of the table shows the standard deviations of this rule for the base-case parameterization of the bounded random walk. As one would expect, the standard deviation of output is lower for the 'less hawkish' rule than for the base-case policy rule, while the standard deviation of inflation is higher.

The middle panel of the table, is more interesting. There we record the loss associated with each rule indexed against the preferences that generate the rules. In each case, we have normalized the losses for the two rules so that, for example, the base-case rule in column (1) is assessed a (normalized) loss of unity for base-case preferences. Similarly, in column (2), the 'less hawkish' rule carries a normalized loss of unity for 'less hawkish' preferences. The interesting result is in the other two entries in these two rows of this panel: notice in column (1) that the performance of the base-case rule under 'less hawkish' preferences is poor: There would be a 81 percent deterioration in performance from the perspective of a 'less hawkish' monetary authority from adopting the base-case rule as an operating procedure. Now examine the performance of the 'less hawkish' rule under basecase preferences in the first column. With a value shown there of 0.88 , we see that the base-case policymaker actually prefers the less hawkish rule. How can this be? Given that the base-case rule is the rule that by construction is supposed to be the preferred rule for base-case preferences, this would appear to be impossible.

The result shown is not an error. It arises because the so-called optimal rule for base-case preferences is actually only optimal conditional on a fixed target rate of inflation (or a random walk). ${ }^{45}$ In the presence of a bound on the random walk, the rule is no longer optimal. This is because the credibility of the target bands does much of the work 
for the authority; given the bands, adding tough inflation targeting to the policy mix only makes matters worse.

\section{Table 5}

\section{Simulated Standard Deviations of Target Band Regimes for Alternative Policies}

$$
\text { Column number --> }
$$

(2)

(3)

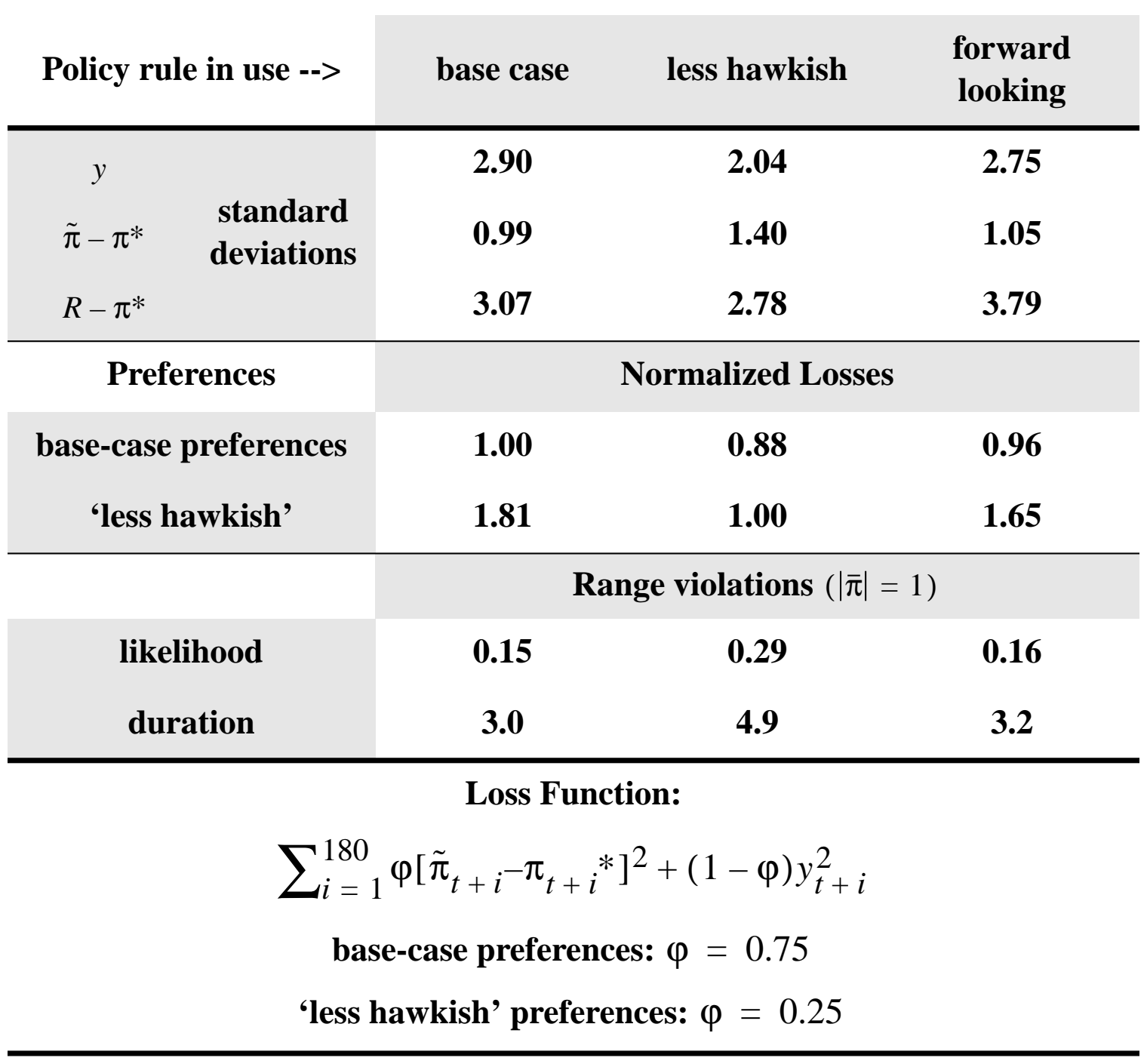

To see why this arises, consider point $\mathrm{E}$ on the thin line in the upper-right quadrant of Figure 9. Observe that the level of output that corresponds with this, point $\mathrm{F}$ in the upper-left

45. The base-case rule is also optimal for the case of a pure random walk, provided that the loss is computed around the (possibly drifting) target rate of inflation, since a fixed target and a pure random walk are identical in expected value terms. 
quadrant is low. With output low, all else equal, the real rate should be low as well. The reason why the real rate is not low is that the monetary authority is trying to move $\tilde{\pi}$ down to $\pi^{*}$, the current target rate of inflation. However private agents know that $\pi^{*}$ is likely to be higher in the future. The inflation rate that arises reflects this expectation on the part of price and wage setters who, after all, must consider current and future costs of adjusting prices: it is optimal for them to avoid reducing prices today if they would only have to raise them again in the near future. But the monetary authority is working against the very effect it has created by adopting target bands in the first place. It follows that a rule that puts less weight on inflation control, in recognition that private agents are doing some of the controlling prices through their expectations, will do better on average.

There are other policy recipes that outperform our base-case rule. Figure 10 provides one example. The thin line in Figure 10 is, once again, our base case. The thick line represents a rule which is forward looking in inflation. In particular, we have replaced the twelve-quarter moving average of current and past inflation less the current target in equation (2) with a four-quarter moving average of current and future inflation less the expected future inflation target:

$$
R_{t}=r r^{*}+\sum_{i=0}^{3} \pi_{t-i} / 4+3.0\left[\sum_{i=0}^{3}\left(\pi_{t+i}-\pi_{t+i} *\right)\right]+0.9 y_{t}
$$

In our base-case scenario, the monetary authority is conducting policy myopically, carrying out short-term target-seeking actions without regard to how the longer-term process of determining the future of the target will play itself out. With the forward-looking rule, the central bank takes into consideration the likelihood of future target changes, even if it is not solving an optimization problem for the future target simultaneously with the determination of the coefficients of the rule. In a more general sense, the monetary authority can be thought of as engaging in a form of inflation forecast targeting, as advocated by Svensson (1997). Or the monetary authority can be thought of as responding to indicators of inflation expectations such as outside forecasts, forward rates, or surveys to set policy, as 
Hall and Mankiw (1994, p. 79) have advocated.

The results in this case are qualitatively similar to those in Figure 6. A forwardlooking monetary authority recognizes that private agents know the target rate of inflation will regress towards the midpoint of the bands over time. By acknowledging this fact in making policy decisions, the monetary authority can improve average policy outcomes in terms of both output and inflation. The middle panel of Table 5 shows us that based on the loss calculation shown, the base-case monetary authority would once again prefer the forward-looking rule to the base-case rule, if only by a slight amount. It would be easy to make too much of this comparison, however, since the real federal funds rate variability is significantly higher for the forward-looking rule than the base-case rule.

Figure 10

Implication of Forward Looking Policy Under Inflation Target Bands

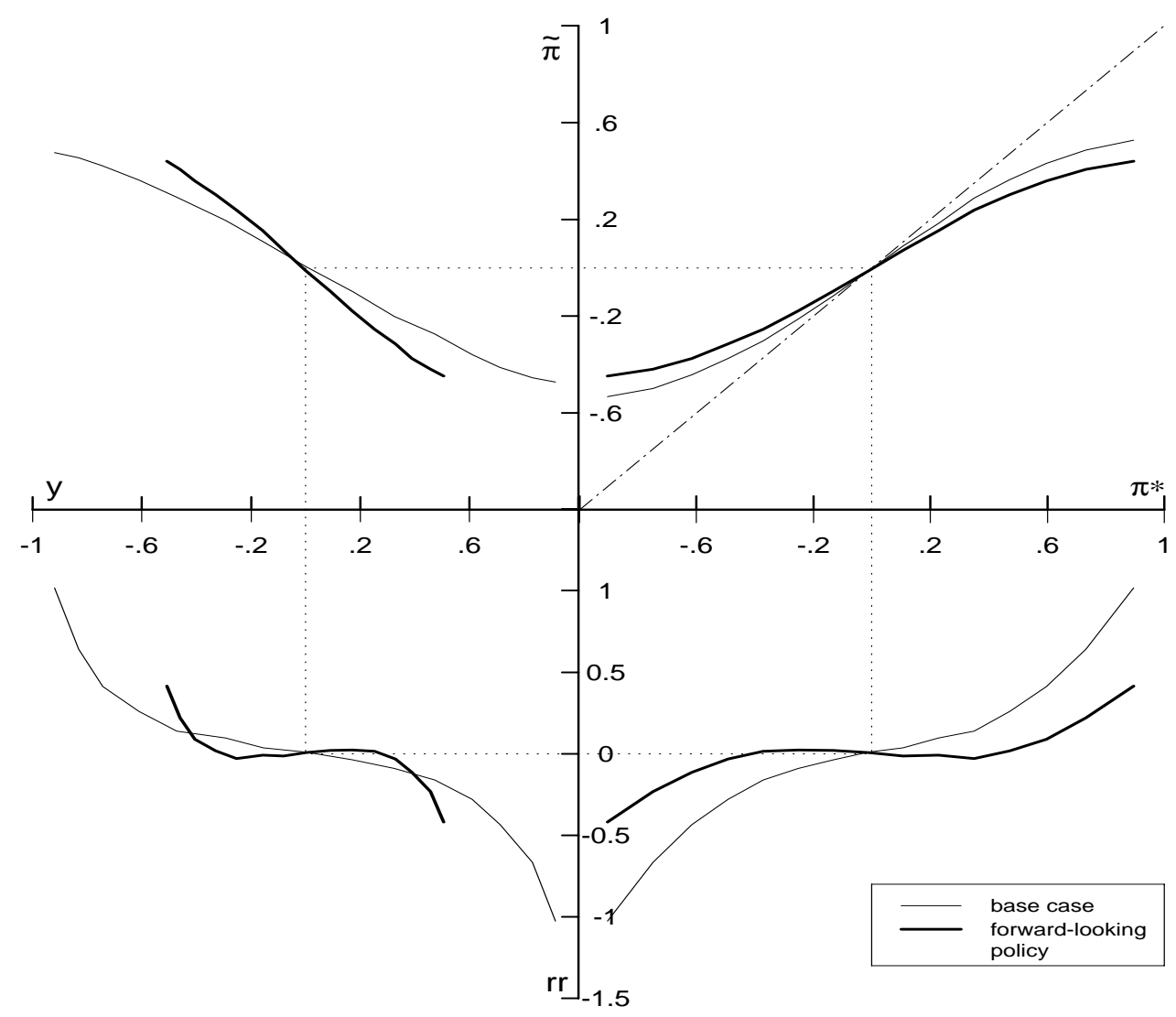

5. Results 
We leave this section of the paper, and this topic, with two observations. First, under the assumptions of this section, it is possible to improve on the economic performance of the simple monetary policy rules that depend, linearly and axiomatically, only on a small set of past values. If monetary policymakers' targets do shift over time but are bounded in some way, and if agents believe in these bounds, then private agents' expectations will be biased, ex post, in a way that is completely consistent with the economic environment. An optimizing policy authority that chooses to ignore such biases will forego improvements in average policy outcomes that can be accrued by encompassing a wide range of indicators of expected future inflation. Similarly, since expectations of target movements on the part of private agents are doing part of the work of the authority in directing price setting behavior toward long-term monetary policy goals, a Pareto improving response of the authority is to substitute away from inflation stabilization and toward output stabilization. Second, our analysis offers a rationale for the passivity in monetary policy operations which many observers have noted appears to be a characteristic of policy in the U.S.. ${ }^{46}$ To see this, examine the thick lines associated with the forward-looking policy rule in the two right-hand side quadrants of Figure 10. The honeymoon effect implies that both inflation and the real interest rate are much flatter than they would be under the random-walk case. Because expectations are being anchored by the credible target band, there is less impetus to adjust the nominal interest rate as the target inflation rate moves over time. Essentially, the public is doing part of the Fed's work for it. We hasten to add, however, that it would be easy to take this argument too far: the lines in our figures represent averages across hundreds of business cycles. Within those cycles, policy is not "passive' at all. Still, this observation, combined with the results portrayed in Figure 9 for the "less hawkish" rule does provide some insights on these issues.

46. See, in particular, Rudebusch (1999), Huizinga and Eijffinger (1999) and Woodford (1999)

5. Results 


\section{Concluding Remarks}

This paper has considered the implications of uncertain policy targets for the conduct of monetary policy. In particular, we have modeled target variability as either a random walk, or a bounded random walk, and examined the implications of the bounds for policy. Uncertain policy targets were argued to be a manifestation of either discretionary policy, or the unwillingness of monetary authorities to respond to disturbances in a timely fashion.

We examined the issue using stochastic simulations of FRB/US, the Board of Governors' rational expectations macroeconometric model of the U.S. economy. We found that credible constraints on the variability of the target rate of inflation can reap benefits in reduced inflation variability, without increasing output variability, in much the same way as indicated in the quotation from Chairman Greenspan at the outset of this article. The question remains as to how a central bank might establish credible constraints on inflation targets. One way to do this is to employ public announcements of a fixed inflation target and a range for inflation outcomes as inflation targeting countries like New Zealand, Canada, the United Kingdom and Sweden have done. Table 4 of this paper described how doing can direct agents' expectations toward the ultimate objective of policy, while still permitting some time variation in policy setting. A central bank that starts out with a reputation for allowing its inflation target to drift can benefit from a "honeymoon effect" wherein the bank reaps the reward of decreases in average inflation variability that are greater than the restriction in the variability of the target. We also found that there are diminishing returns to setting credible inflation target bands: one need not go all the way to a fixed target to reap significant benefits.

Moreover, consistent with popular wisdom, we found that a central bank that enjoys credibility in the range of target drift it will tolerate can exploit that credibility by substituting, at the margin, away from inflation control and toward output stabilization. 
This arises because the expectation that the central bank is likely to contain drift in the target creates a non-linearity in agents' expectations. This pins down expectations of future inflation on the part of firms and workers, and thereby constrains their inclination to respond to shocks by touching off an wage-price spiral. It is this pinning down of future inflation that allows the monetary authority to be less aggressive in its inflation-control policies than would be the case with either a random walk target or a fixed target. 


\section{References}

Anderson, Gary S. (1999), "A Reliable and Computationally Efficient Algorithm for Imposing the Saddle-point Property in Dynamic Models" unpublished manuscript, Division of Monetary Studies, Board of Governors of the Federal Reserve System. Anderson, Gary and George Moore (1985) "A Linear Algebraic Procedure for Solving Linear Perfect Foresight Models" 17,Economics Letters, pp. 247-252.

Bank of Canada (1991) "Background note on the targets" released on 26 February 19991, reprinted in Bank of Canada Review (March 1991)

Barro, Robert and David Gordon (1983) "A Positive Theory of Monetary Policy in a Natural Rate Model" 91,Journal of Political Economy, pp. 589-610.

Bernanke, Benjamin S.; Thomas Laubach, Frederic S. Mishkin and Adam S. Posen (1999) Inflation Targeting: Lessons from the International Experience (Princeton: Princeton University Press).

Blackburn, Keith and Michael Christensen (1989) "Monetary Policy and Credibility: a critical review" 23,Journal of Economic Literature, 1 (March), pp. 1-45.

Blanchard, Olivier J. (1985) "Debt, Deficits and Finite Lives" 93,Journal of Political Economy,2 (April), pp. 223-247.

Blanchard, Olivier J. and Charles M. Kahn (1980) “The Solution of Linear Difference Models Under Rational Expectations" 48,Econometrica,5 (July), pp. 1305-1311.

Blinder, Alan S. (1998) Central Banking in Theory and Practice (Cambridge, MA: MIT Press).

Bomfim, Antulio (1997) "The Equilibrium Fed Funds Rate and the Indicator Properties of Term-Structure Spreads” 35,Economic Inquiry,4 (October), pp. 830-846. 
Bomfim, Antulio; Robert Tetlow; Peter von zur Muehlen, and John Williams (1997)

"Expectations, Learning and the Costs of Disinflation: experiments using the FRB/ US Model” Finance and Economics Discussion Series no. 1997-42, Board of Governors of the Federal Reserve System, (August).

Brayton, Flint and Peter Tinsley (eds.) (1996) "A Guide to FRB/US: A Macroeconometric Model of the United States" Finance and Economics Discussion Series no. 199642, Board of Governors of the Federal Reserve System, (October).

Brayton, Flint; Eileen Mauskopf; David Reifschneider, and John Williams (1997) "The Role of Expectations in the FRB/US Macroeconomic Model” 83,Federal Reserve Bulletin,4 (April), pp. 227-245.

Clarida, Richard; Jordi Gali and Mark Gertler (1998) “Monetary Policy Rules and Macroeconomic Stability: Evidence and Some Theory" NBER working paper no. 6442, (March).

Chari, V. V.; Lawrence J. Christiano and Martin Eichenbaum (1999) "Expectations Traps and Discretion” 81,Journal of Economic Theory,2 (August), pp. 469-492.

Dixit, Avinash (1993) The Art of Smooth Pasting Fundamentals of Pure and Applied Economics, vol 55, (Langhorne, PA: Harwood Academic).

Fair, Ray. C. and John B. Taylor (1983) "Solution and Maximum Likelihood estimation of dynamic nonlinear rational expectations models, 51,Econometrica,4 (July), 11691185.

Freedman, Charles (1995) “The Canadian Experience with Targets for Reducing and Controlling Inflation” Chapter 2 of L. Leiderman and L.E.O. Svensson (eds.) Inflation Targets (London: Centre for Economic Policy Research), pp. 19-31. 
Fuhrer, Jeffrey C. (1994) “Optimal Monetary Policy and the Sacrifice Ratio” in Jeffrey C. Fuhrer (ed.) Goals, Guidelines, and Constraints Facing Monetary Policymakers proceedings of a conferences held at the Federal Reserve Bank of Boston, June 1994. (Boston: Federal Reserve Bank of Boston), pp. 43-69.

Fuhrer, Jeff and George Moore (1995) "Inflation Persistence” 110, Quarterly Journal of Economics, 1 (February), pp. 127-159.

Goodfriend, Marvin (1991) "Interest Rate Smoothing in the Conduct of Monetary Policy" 34,Carnegie-Rochester Conference Series on Public Policy, (December), pp. 7-30. Greenspan, Alan (1998) The Federal Reserve's Semiannual Monetary Policy Report Testimony of Chairman Alan Greenspan before the Subcommittee on Domestic and International Monetary Policy of the Committee on Banking and Financial Services, U.S. House of Representatives, February 24, (Washington: Board of Governors of the Federal Reserve System).

Hall, Robert E. and N. Gregory Mankiw (1994) "Nominal Income Targeting” in N.G. Mankiw (ed.) Monetary Policy (Chicago: University of Chicago Press).

Huizinga, Harry and Sylvester Eijffinger (1999) "Should Monetary Policy be Adjusted Frequently?" Discussion paper no. 2074, Centre for Economic Policy Research, London, (February).

Ireland, Peter N. (1997) “A Small, Structural, Quarterly Model for Monetary Policy Evaluation" 47,Carnegie-Rochester Conference Series on Public Policy (forthcoming).

Johnson, Norman L.; Samuel Kotz and N. Balakrishman (1994) Continuous Univariate Distributions, volume 1 (second edition) (New York: Wiley).

Kohn, Donald L. (1991) “Commentary: The Federal Reserve Policy Process” in Joseph Belongia (ed.) Monetary Policy on the 75th Anniversary of the Federal Reserve System (Boston: Kluwer Academic), pp. 96-103. 
Krugman, Paul R. "Target Zones and Exchange Rate Dynamics" 106,Quarterly Journal of Economics,3 (August), pp. 669-682.

Kydland, Finn E. and Edward C. Prescott (1977) "Rules Rather Than Discretion: The inconsistency of optimal plans" 85,Journal of Political Economy, pp. 473-492.

Laffargue, Jean-Pierre (1990) "Résolution d'un Modèle Macroéconmétrique avec Anticipations Rationnelles" 17,Annales d'Economie et Statistique , pp. 97-119.

Meltzer, Allan H. (1991) "The Fed at Seventy-Five" in Joseph Belongia (ed.) Monetary Policy on the 75th Anniversary of the Federal Reserve System (Boston: Kluwer Academic), pp. 3-65.

Meyer, Laurence H. (1997) "Monetary Policy Objectives and Strategy" 32,Business Economics,1 (January), pp. 17-21.

Meyer, Laurence H. (1998a) “The Strategy of Monetary Policy” Alan R. Holmes Lecture, Middlebury College, Middlebury, VT (March 16).

Meyer, Laurence H. (1998b) "Come with Me to the FOMC" The Gillis Lecture, Willamette University, Salem, OR (April 2).

Orphanides, Athanasios and David Wilcox (1996) "The Opportunistic Approach to Disinflation" Financial and Economics Discussion Series paper no. 1996-24, Board of Governors of the Federal Reserve System, (May)

Orphanides, Athanasios; David H. Small, Volker Wieland, and David A. Wilcox (1997) “A Quantitative Exploration of the Opportunistic Approach to Disinflation" Finance and Economics Discussion Series paper no. 1997-36, Board of Governors of the Federal Reserve System, (June).

Reifschneider, David; Robert Tetlow and John C. Williams (1999) “Aggregate Disturbances, Monetary Policy, and the Macroeconomy: The FRB/US Perspective" 85,Federal Reserve Bulletin,1 (January) pp. 1-19. 
Rotemberg, Julio and Michael Woodford (1997) “An Optimization-Based Econometric Framework for the Evaluation of Monetary Policy" NBER Macroeconomics Annual, 1997.

Rudebusch, Glenn (1999) "Is the Fed Too Timid? Monetary Policy in an Uncertain World" unpublished manuscript, Federal Reserve Bank of San Francisco (March).

Siklos, Pierre L. (1997) "Charting a Future for the Bank of Canada: Inflation Targets and the Balance between Autonomy and Accountability" in David Laidler (ed.) Where Do We Go From Here?: Inflation Targets in Canada's Monetary Policy Regime. Policy Study no. 29 (Toronto: C.D. Howe Institute).

Summers, Lawrence (1991) "How Should Long Term Monetary Policy Be Determined" 23,Journal of Money, Credit and Banking, August 1991, pp. 625-631.

Svensson, Lars E.O. (1997) "Inflation Forecast Targeting: Implementing and Monitoring Inflation Targets" 41,European Economic Review,6 (June) pp. 1111-1146.

Taylor, John B. (1993) “Discretion versus Policy Rules in Practice” 39,CarnegieRochester Conference Series on Public Policy,2 (Autumn), pp. 195-214.

Taylor, John B. (1994) “The Inflation/Output Variability Trade-off Revisited” in Jeffrey C. Fuhrer (ed.) Goals, Guidelines, and Constraints Facing Monetary Policymakers proceedings of a conferences held at the Federal Reserve Bank of Boston, June 1994. (Boston: Federal Reserve Bank of Boston), pp. 21-38.

Williams, John C. (1999) "Simple Rules for Monetary Policy” Finances and Economics Discussion Series paper no. 1999-12, Board of Governors of the Federal Reserve System, (February).

Woodford, Michael (1999) “Optimal Monetary Policy Inertia” working paper no. 7261, National Bureau of Economic Research, Cambridge, MA, (July). 